\title{
Development of Useful Reactions Involving Tandem Cyclizations Based on the Novel Reactivities of Allenic Compounds
}

\author{
Hiroaki OHNO $^{1)}$ \\ Graduate School of Pharmaceutical Sciences, Osaka University; 1-6 Yamadaoka, Suita, Osaka 565-0871, Japan.
} Received June 13, 2005

\begin{abstract}
This review highlights author's recent study on allenic compounds. In the first section, organocopper-mediated ring-opening reaction of ethynylaziridines and palladium-catalyzed reductive synthesis of allenes including those which are not accessible by other means, are described. In the second section, palladium-catalyzed stereoselective cyclization of allenes and tandem reaction leading to aziridines, pyrrolidines, benzoisoindoles, and cyclopropanes are presented. The final section presents aziridination and medium-ring formation by intramolecular reaction of bromoallenes, which are scarcely investigated until quite recently. The latter reaction is based on our recent discovery that bromoallenes can act as allylic dication equivalents in the presence of a palladium catalyst and alcohol.
\end{abstract}

Key words allene; palladium; heterocycle; aziridine; medium-sized ring; tandem reaction

\section{Introduction}

Allene is a versatile functionality which serves as either a nucleophile or an electrophile and also as a precursor for cycloaddition reactions. $^{2-7)}$ This multi-reactivity and existence of two orthogonal $\pi$-bonds attract considerable attention of organic chemists. In particular, a series of excellent results in the field of transition-metal catalyzed reaction of allenes are now being produced. ${ }^{8-10)}$ Introduction of an additional functionality to allenes makes them a multifunctional chiral C-3 unit which can be potentially applied to novel tandem reactions. This review presents our recent study of allene chemistry, including 1) synthesis of allenes, 2) palladium-catalyzed cyclization of allenes including tandem cyclization, and 3) cyclization of bromoallenes to aziridines and mediumsized heterocycles.

\section{Synthesis of Allenes}

2.1. Stereoselective Synthesis of Chiral Amino Allenes by Organocopper-Mediated anti-SN2'-Substitution Reaction of Chiral Ethynylaziridines ${ }^{11,12}$ Among various substituted allenes, amino allenes are versatile building blocks for constructing azacycles. However, a scan of the literature has revealed a surprising paucity of methods that facilitate the synthesis of chiral internal allenes bearing a nitrogen functionality separated from the allenic carbon atom only by one carbon atom. ${ }^{13}$ ) The author planned to synthesize chiral amino allenes by organocopper-mediated ring-opening reaction of ethynylaziridines.

The stereochemical course of organocopper-mediated $S_{N} 2^{\prime}$ substitution of propargylic compounds has been well documented $^{14,15)}$ : they usually undergo highly stereoselective antifacial reactions; i.e., the $S_{N} 2^{\prime}$ displacement generally pro- ceeds anti to the leaving group. The organocopper-mediated ring-opening reaction of propargylic epoxides also affords the corresponding hydroxy allenes in a highly regio- and anti-S $S_{N} 2^{\prime}$-selective manner. ${ }^{16)}$ Interestingly, it has been reported by Alexakis et al. that the $S_{N} 2^{\prime}$ displacement of the propargylic epoxides or ethers can lead to either anti or syn products, depending on the reaction conditions or copper reagents used. ${ }^{17,18)}$ It is of considerable interest to determine whether chiral ethynylaziridines can be transformed diastereoselectively into chiral amino allenes by the reaction with organocopper reagents.

The requisite $N$-arylsulfonylated 2,3-trans- and 2,3-cis-3alkyl-2-ethynylaziridines $\mathbf{1}$ and $\mathbf{3}$, respectively, with high optical purities $(>98 \%$ ee) were prepared in a straightforward manner from natural $\alpha$-amino acids following our recently published procedures. ${ }^{19,20)}$ Although the reaction of ethynylaziridines 1 with Gilman-type reagent, $\mathrm{R}_{2} \mathrm{CuLi} \cdot \mathrm{nLiX}(\mathrm{X}=\mathrm{Cl}$ or $\mathrm{Br}$ ) or $\mathrm{R}_{2} \mathrm{CuLi} \cdot \mathrm{LiCN} \cdot \mathrm{nLiX}$ afforded a mixture of products including syn- and anti-SN2' products, and reduction product. In contrast, it was found that organocyanocuprates, $\mathrm{RCu}(\mathrm{CN}) \mathrm{M} \cdot \mathrm{nLiX}(\mathrm{M}=\mathrm{Li}$ or $\mathrm{MgBr}, \mathrm{X}=\mathrm{Cl}$ or $\mathrm{Br})$, are the reagent of choice for the ring-opening reaction, giving excellent isolated yields of the corresponding anti-SN2' products (Chart 1). For example, exposure of 1 to $\mathrm{MeCu}(\mathrm{CN}) \mathrm{Li}$. $2 \mathrm{LiCl}, i-\mathrm{PrCu}(\mathrm{CN}) \mathrm{MgBr} \cdot 2 \mathrm{LiCl}, n-\mathrm{BuCu}(\mathrm{CN}) \mathrm{Li} \cdot 2 \mathrm{LiCl}$, or $n-\mathrm{Bu}_{3} \mathrm{SnCu}(\mathrm{CN}) \mathrm{Li} \cdot 2 \mathrm{LiCl}$ yields the corresponding ringopened products $\mathbf{2 a}-\mathbf{d}$ in high yields. The 2,3-trans-isomer 3 also gave exclusively the anti- $S_{N} 2^{\prime}$ products 4 . In all cases examined, regio- or stereoisomeric products were not detected in the reaction mixture.

The stereochemical course of the ring-opening reaction of ethynylaziridines is shown in Chart 2. Similar to other related 
substitution of propargylic compounds, the reaction of aziridines generally proceeds anti to the leaving nitrogen atom.

2.2. Synthesis of Allenes from Allylic Alcohol Derivatives Bearing a Bromine Atom Using a Palladium(0)/Diethylzinc System ${ }^{21,22)}$ In the course of the author's recent study involving synthesis of ethynylaziridines, ${ }^{19,20)}$ it was found that the allylic mesylates having a bromine atom on the central carbon can be converted into the allenes on treatment with diethylzinc in the presence of a palladium(0) catalyst. Although there have been some reports describing related synthesis of allenes, ${ }^{23-25)}$ no systematic investigation involving the synthesis of allenes from such class of compounds has been carried out, and a catalytic synthesis of al-

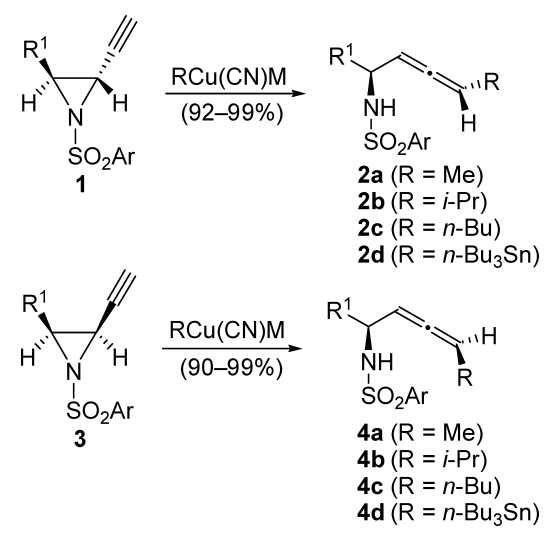

Chart 1. Synthesis of $\alpha$-Amino Allenes by Ring-Opening Reaction of 2Ethynylaziridines
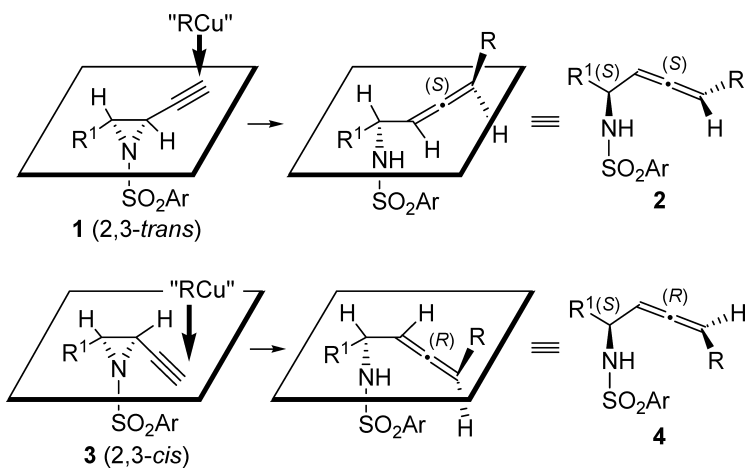

Chart 2. Stereochemical Course of the Ring-Opening Reaction of 2Ethynylaziridines lenes from such substrates is unknown. As described above (Section 2.1), internal allenes (1,3-disubstituted allenes) bearing an $N$-protected amino group could be readily synthesized from ethynylaziridines by treatment with organocopper reagents $^{11,12)}$; however, preparation of monosubstituted allenes without contaminating the corresponding acetylene by the use of organocopper chemistry has proven to be quite difficult. Although reliable synthetic methods of terminal allenes have been already developed, some of these are unsuitable for the synthesis of allenes bearing a nitrogen functionality. $^{26-28)}$ The potential utility of the synthesis of allenes by a palladium(0)/diethylzinc system, especially for the synthesis of terminal allenes bearing an amino group, led us to a detailed investigation of this reaction.

First, various substrates bearing an amino group for the palladium-catalyzed reduction was examined. As shown in Fig. 1, both the $(Z)$ - and $(E)$-mesylates 5 and $\mathbf{6}$ were converted into the corresponding $\alpha$-amino allenes 7-10 in good to high yields by exposure to $\mathrm{Pd}\left(\mathrm{PPh}_{3}\right)_{4}(10 \mathrm{~mol} \%)$ and $\mathrm{Et}_{2} \mathrm{Zn}$ ( 2 eq) in THF for 20 to $60 \mathrm{~min}$. Similarly, $\beta$-amino allene 11 and $\gamma$-amino allenes $\mathbf{1 2}$ and $\mathbf{1 3}$ were obtained in good yields from the corresponding mesylates.

To expand the synthetic utility of the reaction, the synthesis of various alkyl and aryl allenes lacking an amino group was investigated. Monoalkyl allenes 14 was synthesized in good yield from $(Z)$ - or $(E)$-mesylates. Similarly, bis(mesylate)s were converted into the bis(allene) $\mathbf{1 5}$. This allene synthesis is also applicable to the conversion of secondary alcohol derivatives into the corresponding internal allenes such as $\mathbf{1 6}$ and 18. It should be noted that synthesis of the mesylates 5 having an aryl group at the $\mathrm{C}-1$ or $\mathrm{C}-3$ position $\left(\mathrm{R}^{1}\right.$ or $\mathrm{R}^{2}=\mathrm{Ar}$ ) was quite difficult, presumably due to the conjugated system. Accordingly, the reaction of the corresponding acetates and trichloroacetates was investigated in such cases. When using the acetate for the synthesis of aryl allene 17, the reaction proceeded quite slowly at room temperature, and prolonged reaction time was required. In contrast, when using the trichloroacetate, the reaction was completed at room temperature within $30 \mathrm{~min}$, and $69 \%$ of the aryl allene 17 was obtained. From these observations, it is obvious that this allene synthesis is useful for the synthesis of allenes bearing aminoalkyl, alkyl, and aryl group(s) including terminal, internal, and bis(allene)s. In all cases, no acetylenic compounds were detected.

Next, the influence of the stereochemistry of the mesyloxy group, on the axial chirality of the resulting allenes, was in-

Hiroaki Ohno was born in 1973 in Kushiro, Hokkaido, Japan. He graduated with a B.S. degree in Pharmaceutical Sciences from Kyoto University in 1996. He received his M.S. degree from the same university under the direction of Professor Toshiro Ibuka (1998). After his doctoral work in Kyoto University (1998-1999; during 1999 he worked as a Research Fellow of the Japan Society for the Promotion of Science), he joined the research group of Professor Tetsuaki Tanaka at Osaka University as a Research Associate. In 2002 he obtained his Ph.D. from Kyoto University working on the stereoselective synthesis of chiral alkenylaziridines. He received the Pharmaceutical Society of Japan Kinki Branch Award for Young Scientists (2001) and the Pharmaceutical Society of Japan Award for Young Scientists (2005). He started his carrier as an Associate Professor of Kyoto University (Professor Nobutaka Fujii's research group) in July of 2005.

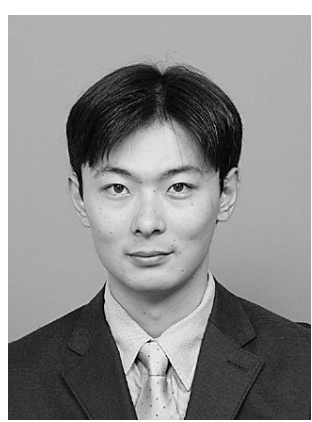

Hiroaki Ohno 
<smiles>[R]C=C(Br)C([R])OC</smiles>

(Z)-5

(E)-6

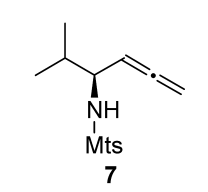

from 5: $60 \mathrm{~min}, 86 \%$ from 6: $30 \mathrm{~min}, 86 \%$<smiles>C=CC(Cc1ccccc1)NN(C)S(=O)(=O)c1ccccc1</smiles>

from 5: $60 \mathrm{~min}, 85 \%$ from 6: $60 \mathrm{~min}, 90 \%$

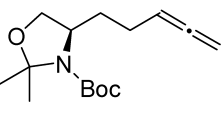

13

from 5: $60 \mathrm{~min}, 69 \%$

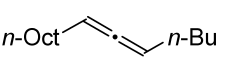

16

from 5: $15 \mathrm{~min}, 77 \%$

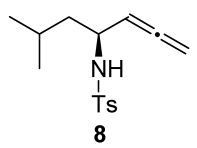

from 5: $40 \mathrm{~min}, 86 \%$

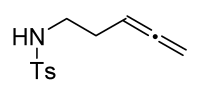

11 from 6: $60 \mathrm{~min}, 66 \%$

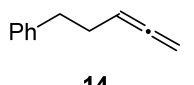

14

from 5: $60 \mathrm{~min}, 78 \%$ from $(Z, Z): 90 \mathrm{~min}, 77 \%$ from 6: $60 \mathrm{~min}, 62 \%$ from $(E, Z)$ : $90 \mathrm{~min}, 74 \%$

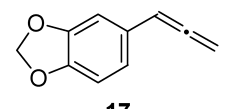

17

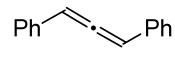

18

from 5: $20 \mathrm{~min}, 69 \%^{c)} \quad$ from 5: $30 \mathrm{~min}, 83 \%^{c)}$ from 6: $40 \mathrm{~min}, 87 \%$

from 5: $30 \mathrm{~min}, 69 \%^{b)}$

Fig. 1. Synthesis of Allenes Using a Palladium(0)/Diethylzinc System ${ }^{a}$ a) Reactions were carried out in THF at room temperature under argon using $\mathrm{Pd}\left(\mathrm{PPh}_{3}\right)_{4}(10 \mathrm{~mol} \%)$ and $\mathrm{Et}_{2} \mathrm{Zn}$ (2 eq), unless otherwise stated. b) $4 \mathrm{~mol} \%$ of $\mathrm{Pd}\left(\mathrm{PPh}_{3}\right)_{4}$ was used. c) Since preparation of the mesylates was difficult, the corresponding trichloroacetates were used. Mts=2,4,6-trimethylphenylsulfonyl.

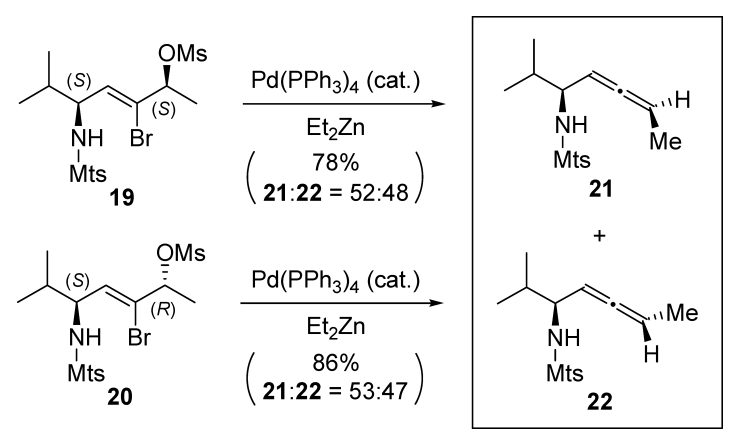

Chart 3. Formation of Allenes from the Mesylates $\mathbf{1 9}$ and $\mathbf{2 0}$

vestigated. As shown in Chart 3, the reaction of the $(S, S)$-mesylate 19 with $\mathrm{Et}_{2} \mathrm{Zn}$ in the presence of catalytic $\mathrm{Pd}\left(\mathrm{PPh}_{3}\right)_{4}$ afforded a mixture of amino allenes 21 and 22 in 78\% yield $(21: \mathbf{2 2}=52: 48)$. Similarly, the $(S, R)$-mesylate 20 also gave an almost equimolar mixture of $\mathbf{2 1}$ and 22 ( $86 \%$ yield, $21: 22=53: 47)$. Accordingly, it is apparent that the chirality of the substrates is not reflected to the axial chirality of the resulting allenes.

These results can be rationalized as follows (Chart 4): oxidative addition of $\mathbf{2 3}$ to palladium( 0 ) will afford $\eta^{3}$-allylpalladium(II) intermediate $\mathbf{2 4}$ with inversion of configuration. While $s y n$-1,2-elimination of palladium(II) bromide from $\mathbf{2 6}$ would give $(R)-27$, elimination from 29 would give $(S)-27$. Since an almost $1: 1$ mixture of $\mathbf{2 1}$ and $\mathbf{2 2}$ was obtained from
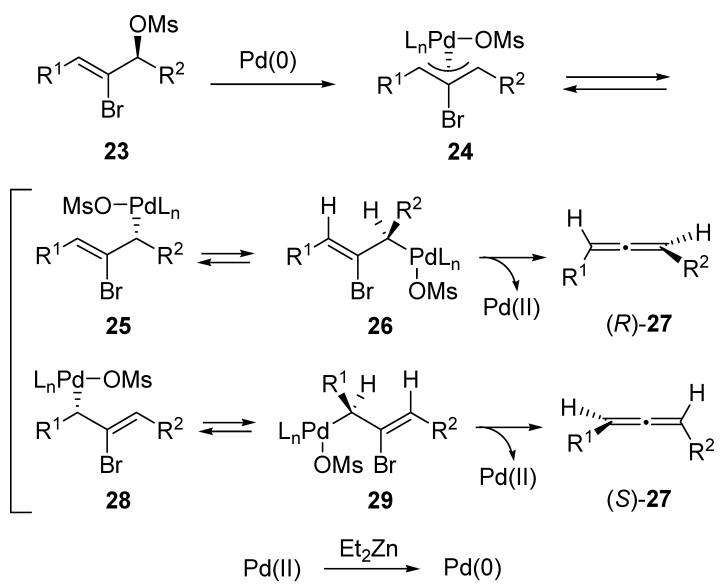

$$
(\overbrace{\mathrm{R}^{1} \overbrace{\mathrm{Br}}^{\mathrm{Zn}} \mathrm{R}^{2}-\mathrm{X}}^{\overbrace{\mathrm{A}}^{2}})
$$

Chart 4. Stereochemical Course of the Reductive Allene Synthesis from Mesylates

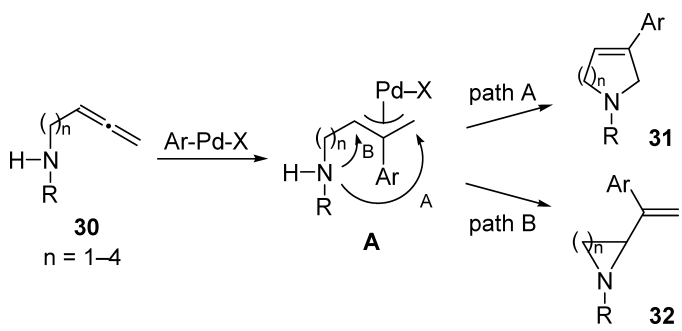

Chart 5. Cyclization of Amino Allenes

either 19 or $\mathbf{2 0}$ (Chart 3), the author speculates that both $\mathbf{2 6}$ and $\mathbf{2 9}$ are competent intermediates in the reaction. The generated palladium(II) species would be converted into palla$\operatorname{dium}(0)$ by the action of $\mathrm{Et}_{2} \mathrm{Zn}$, which is well accepted in the literature. ${ }^{29)}$ Although $\mathrm{Et}_{2} \mathrm{Zn}$ is not essential when $1 \mathrm{eq}$ of $\mathrm{Pd}\left(\mathrm{PPh}_{3}\right)_{4}$ was employed, another mechanism via transmetallation of the $\eta^{3}$-allylpalladium(II) intermediate with diethylzinc to form $\mathbf{A}$ cannot be ruled out. ${ }^{30,31)}$

\section{Palladium-Catalyzed Cyclization of Allenes}

3.1. Stereoselective Synthesis of 2-Alkenylaziridines and 2-Alkenylazetidines by Palladium-Catalyzed Intramolecular Amination of $\boldsymbol{\alpha}$ - and $\boldsymbol{\beta}$-Amino Allenes ${ }^{32-34)}$ Transition metal-catalyzed cyclization of allenes bearing a (pro-)nucleophilic functionality such as oxygen, nitrogen, and carbon has attracted much attention in recent years. ${ }^{35,36)}$ Particularly, cyclization of amino allenes using such metals as $\operatorname{Pd}(0$ or II $),{ }^{37-45)} \operatorname{Ag}(\mathrm{I}),{ }^{46-50)}$ and organolanthanides ${ }^{51)}$ has become quite useful methodology for the synthesis of fiveor six-membered azacycles, and several groups have applied such cyclization to the total synthesis of natural products. ${ }^{52-54)}$ It is well documented that cyclization of amino allene 30 with a one- or two-carbon tether between the allene and the nitrogen atom $(\mathrm{n}=1$ or 2$)$ yields five- or six-membered azacycles $31(n=1$ or 2$)$ selectively by path A (Chart $5)$, while an amino allene bearing a longer carbon tether $(n=3$ or 4$)$ also affords five- or six-membered rings $32(n=3$ 
or 4) via path B. In contrast, ring-closure of amino allenes bearing a shorter carbon chain $(n=1$ or 2$)$ yielding three- or four-membered azacycles (path B) was unprecedented. ${ }^{55-59)}$ Recent development of aziridine and azetidine chemistry prompted us to synthesize these compounds bearing a wide variety of alkenyl groups via cyclization of amino allenes. ${ }^{60-63)}$ It was of great interest to determine whether amino allenes can be cyclized into strained aziridines and azetidines using a transition-metal-based catalytic system and whether the axial chirality of the amino allenes influences the chemo- and stereoselectivity of the cyclization process.

Amino allenes were prepared by use of the organocoppermediated ring-opening reaction of chiral ethynylaziridines as already described in Section 2.1. First, the cyclization of $\alpha$ amino allenes under various reaction conditions was investigated. To the author's initial disappointment, exposure of 33a and 34a to the known reaction conditions $\left[\mathrm{Pd}\left(\mathrm{PPh}_{3}\right)_{4}, \mathrm{~K}_{2} \mathrm{CO}_{3}\right.$, and iodobenzene in $\mathrm{DMF}]^{39)}$ afforded undesired five-membered rings 35a and 36a, respectively, although in a stereoselective manner (Chart 6). Other known cyclization using $\mathrm{Ag}(\mathrm{I})$ again resulted in the formation of a five-membered ring as the sole isolable product.

After considerable unsuccessful experimentation, the expected aziridine formation was realized when the palla$\operatorname{dium}(0)$-catalyzed cyclizations were conducted in 1,4-dioxane. The results are summarized in Table 1. Typically, a dioxane solution of the amino allene 33a, iodobenzene, $\mathrm{K}_{2} \mathrm{CO}_{3}$, and a catalytic amount of $\mathrm{Pd}\left(\mathrm{PPh}_{3}\right)_{4}(4 \mathrm{~mol} \%)$ was refluxed yielding 2,3-cis- and 2,3-trans-2-alkenylaziridines 37a and 38a in an $82: 18$ ratio in a good combined yield ( $80 \%$, entry 1). Arylation takes place on the central carbon of the allenic moiety, in the same manner as is described in the previous cyclization of amino allenes. Similarly, by using $p$-iodotoluene instead of iodobenzene, the expected aziridines $37 \mathbf{e}$ and 38e were obtained (entries 5, 10).

The previous studies on the alkenylaziridines by the author's group revealed that 2,3-cis-2-alkenylaziridines are relatively more stable than their 2,3-trans-isomers, and that 2,3trans-isomers can be easily isomerized into their cis-isomers upon treatment with palladium(0), via $\eta^{3}$-allylpalladium(II) intermediates. $^{64-67)}$ However, it has been proven that upon exposure of the 2,3-trans-2-alkenylaziridines of the type $\mathbf{3 8}$ having a methyl substituent on the double bond to the cyclization conditions, isomerization to the cis isomer $\mathbf{3 7}$ was observed only to a small extent. This is presumably due to the lower reactivity of alkenylaziridines $\mathbf{3 7 / 3 8}$ having a highly substituted vinyl group toward palladium $(0)$, and palladium $(0)$ hence reacts with iodobenzene preferably to form phenylpalladium(II) iodide. Accordingly, the stereoselective formation of alkenylaziridines $\mathbf{3 7}$ and $\mathbf{3 8}$ (Table 1) would be mainly controlled kinetically.

A plausible rationale for the stereoselectivities of the aziridination reaction of internal amino allenes is depicted in Chart 7. Phenylpalladium(II) iodide, formed in situ from iodobenzene and $\operatorname{Pd}(0)$, would generate $\eta^{3}$-allylpalladium complexes by the reaction with $(S, \mathrm{a} S)$-33 approaching from the less hindered face. Predominant formation of the complex 39 (path A) over 40 (path B) can be expected due to the relatively small steric repulsion of phenylpalladium(II) iodide with a methyl group than with an aminomethyl group $\left(\mathrm{R}_{\mathrm{L}}\right)$. The cis-E-alkenylaziridine 37 would be formed as a

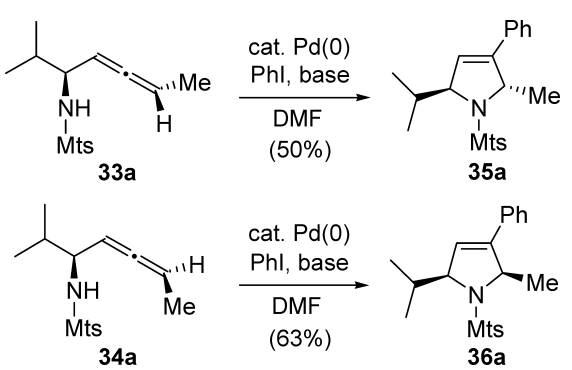

Chart 6. Formation of Five-Membered Rings from $\alpha$-Amino Allenes

Table 1. Palladium(0)-Catalyzed Aziridination of the $\alpha$-Amino Allenes 33 and $34^{a)}$

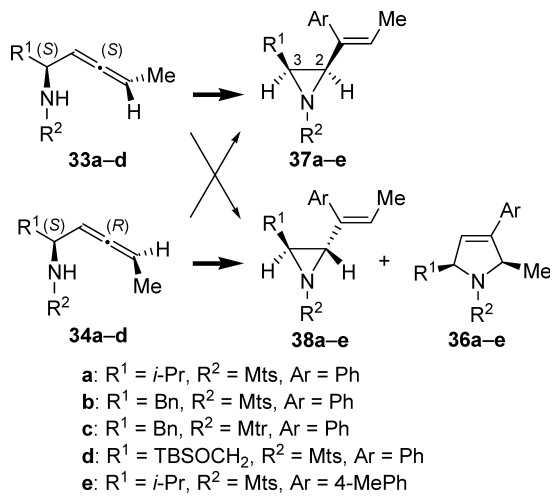

\begin{tabular}{rrrlr}
\hline \hline Entry & Allene & ArI & \multicolumn{1}{c}{ Product ratio $^{b)}$} & $\begin{array}{c}\text { Yield }^{c)} \\
(\mathbf{0})\end{array}$ \\
\hline 1 & 33a & PhI & 37a $: \mathbf{3 8 a}=82: 18$ & 80 \\
2 & 33b & PhI & 37b $: \mathbf{3 8 b}=85: 15$ & 79 \\
3 & 33c & PhI & 37c $: \mathbf{3 8 c}=80: 20$ & 79 \\
4 & 33d & PhI & 37d $: \mathbf{3 8 d}=72: 28$ & 74 \\
5 & 33a & $4-\mathrm{MePhI}$ & $\mathbf{3 7 e}: \mathbf{3 8 e}=91: 9$ & 64 \\
6 & 34a & PhI & $\mathbf{3 7 a}: \mathbf{3 8 a}: \mathbf{3 6}=2: 90: 8$ & 79 \\
7 & 34b & PhI & $\mathbf{3 7 b}: \mathbf{3 8 b}: \mathbf{3 6}=17: 67: 16$ & 73 \\
8 & 34c & PhI & $\mathbf{3 7 c}: \mathbf{3 8 c}: \mathbf{3 6 c}=17: 78: 5$ & 77 \\
9 & 34d & PhI & $\mathbf{3 7 d}: \mathbf{3 8 d}: \mathbf{3 6 d}=23: 64: 13$ & 71 \\
10 & 34a & $4-\mathrm{MePhI}$ & $\mathbf{3 7 e}: \mathbf{3 8 e}: \mathbf{3 6 e}=12: 85: 3$ & 44 \\
\hline
\end{tabular}

a) All reactions were carried out in 1,4-dioxane under reflux using $\operatorname{Pd}\left(\mathrm{PPh}_{3}\right)_{4}(4$ $20 \mathrm{~mol} \%$ ), $\mathrm{K}_{2} \mathrm{CO}_{3}$ (4 eq), and ArI (4 eq). b) Ratios were determined by ${ }^{1} \mathrm{H}-\mathrm{NMR}$ $(270 \mathrm{MHz})$ or isolation of the products. c) Isolated yields. Mtr=4-methoxy-2,3,6trimethylphenylsulfonyl.

major product by the intramolecular nucleophilic attack of the nitrogen onto the stable $s y n-\eta^{3}$-allylpalladium complex 41 derived from $39^{68)}$ via $\eta^{3}-\eta^{1}-\eta^{3}$ mechanism, reproducing palladium( 0$)$. Formation of the minor trans- $E$-alkenylaziridine 38 can be rationalized by path $\mathrm{B}$, in that the allylpalladium complex $\mathbf{4 0}$ is isomerized into stable $\mathbf{4 2}$, followed by cyclization. The predominant formation of the trans- $(E)$ alkenylaziridine $\mathbf{3 8}$ from $(S, \mathrm{a} R)-\mathbf{3 4}$ can be explained in a similar manner. The significant effect of the solvent on the regioselectivity of the reaction was not rationalized at the present stage of the authors' understandings.

Next, cyclization of $\beta$-amino allenes for the synthesis of alkenylazetidines was investigated. Considering the results of the palladium-catalyzed cyclization of $\alpha$-amino allenes, the author anticipated that the choice of 1,4-dioxane would also be suitable for the cyclization of $\beta$-amino allenes. Treatment of the $\beta$-amino allene 43a with iodobenzene, $\mathrm{K}_{2} \mathrm{CO}_{3}$, and catalytic $\mathrm{Pd}\left(\mathrm{PPh}_{3}\right)_{4}$ in dioxane yielded an isomeric mixture of 


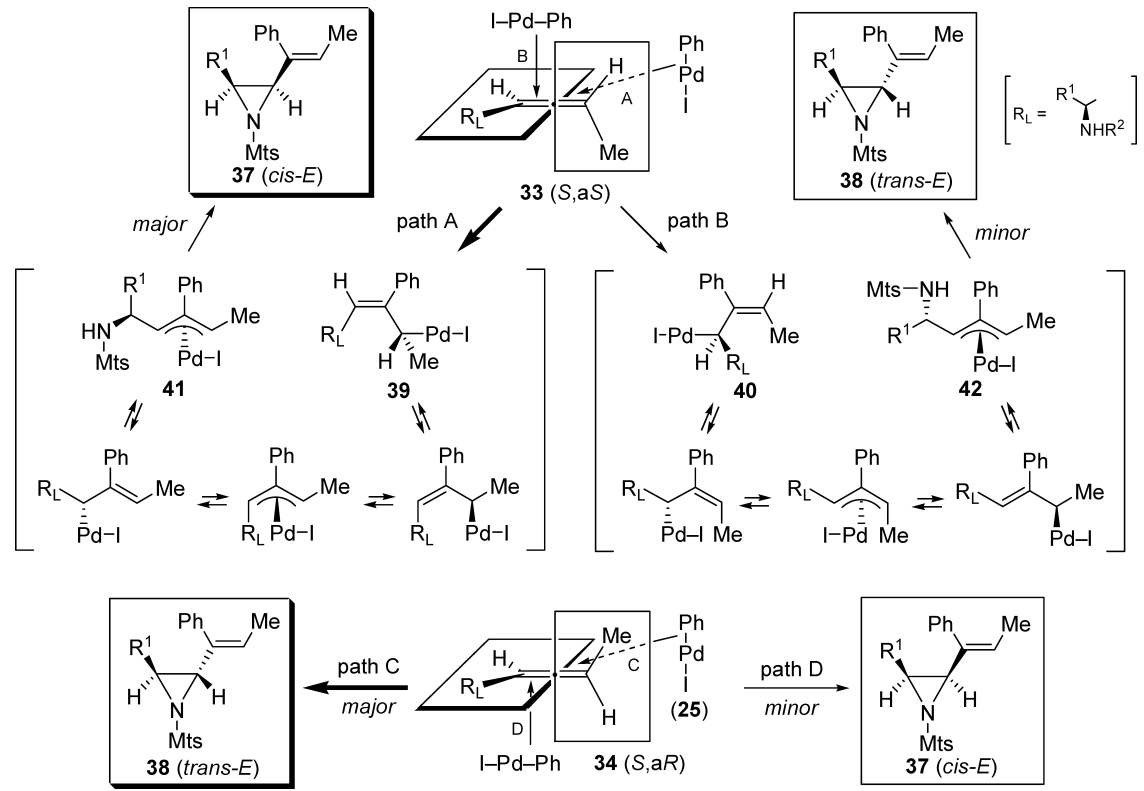

Chart 7. One Plausible Rationale for the Stereoselective Aziridination of $\mathbf{3 3}$ and $\mathbf{3 4}$

Table 2. Palladium(0)-Catalyzed Azetidine Synthesis from $\beta$-Amino Allenes ${ }^{a)}$
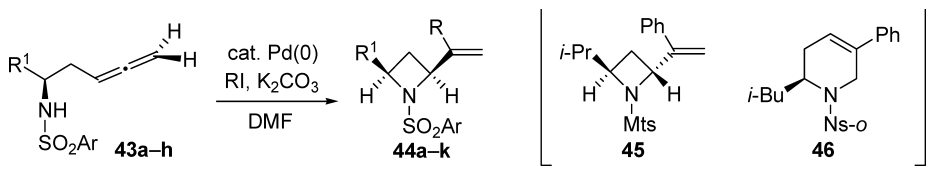

\begin{tabular}{|c|c|c|c|c|c|c|c|}
\hline Entry & Allene & $\mathrm{R}^{1}$ & $\mathrm{R}^{2}$ & RI & $\begin{array}{l}\text { Reaction time } \\
\text { (h) }\end{array}$ & Product ratio ${ }^{b)}$ & $\begin{array}{c}\text { Yield }^{c)} \\
(\%)\end{array}$ \\
\hline $1^{d)}$ & $43 a$ & $i-\operatorname{Pr}$ & Mts & $\mathrm{PhI}$ & 4 & $44 \mathbf{a}: \mathbf{4 5}=82: 18$ & 91 \\
\hline 2 & $43 a$ & $i-\operatorname{Pr}$ & Mts & $\mathrm{PhI}$ & 2 & $44 a=100$ & 98 \\
\hline 3 & $43 b$ & $i-\mathrm{Bu}$ & Mts & $\mathrm{PhI}$ & 3.5 & $\mathbf{4 4} b=100$ & 84 \\
\hline 4 & $43 c$ & $i-\mathrm{Bu}$ & Ts & $\mathrm{PhI}$ & 3 & $44 c=100$ & 89 \\
\hline 5 & 43d & $i$-Bu & $\left.o-\mathrm{Ns}^{e}\right)$ & $\mathrm{PhI}$ & 0.75 & $\mathbf{4 4 d}: \mathbf{4 6}=62: 38$ & 87 \\
\hline 6 & $43 \mathrm{e}$ & $\mathrm{Bn}$ & Ts & $\mathrm{PhI}$ & 1 & $44 e=100$ & 89 \\
\hline 7 & $43 \mathrm{f}$ & $\mathrm{TBSOCH}_{2}$ & Mts & $\mathrm{PhI}$ & 1.5 & $\mathbf{4 4 f}=100$ & 53 \\
\hline 8 & $43 g$ & $\mathrm{MeO}_{2} \mathrm{C}\left(\mathrm{CH}_{2}\right)_{2}$ & Mts & $\mathrm{PhI}$ & 1 & $\mathbf{4 4 g}=100$ & 67 \\
\hline 9 & $43 \mathrm{~h}$ & $\mathrm{MeO}_{2} \mathrm{C}\left(\mathrm{CH}_{2}\right)_{2}$ & Mtr & $\mathrm{PhI}$ & 1.5 & $44 h=100$ & 73 \\
\hline 10 & 43b & $i-\mathrm{Bu}$ & Mts & $3-\mathrm{NO}_{2} \mathrm{PhI}$ & 1 & $44 \mathbf{i}=100$ & 22 \\
\hline 11 & $43 b$ & $i-\mathrm{Bu}$ & Mts & $\mathrm{PhCH}=\mathrm{CHBr}$ & 0.75 & $\mathbf{4 4} \mathbf{j}=100$ & 68 \\
\hline 12 & $43 \mathrm{e}$ & $\mathrm{Bn}$ & Ts & 4-MePhI & 1.5 & $44 k=100$ & 81 \\
\hline
\end{tabular}

a) All reactions were carried out in DMF at $70{ }^{\circ} \mathrm{C}$ using $\mathrm{Pd}\left(\mathrm{PPh}_{3}\right)_{4}(10 \mathrm{~mol} \%), \mathrm{K}_{2} \mathrm{CO}_{3}(4 \mathrm{eq})$, and $\mathrm{RI}(4$ eq) unless otherwise stated. $b)$ Ratios were determined by ${ }^{1} \mathrm{H}-\mathrm{NMR}$ $(270 \mathrm{MHz})$ or isolation of the products. c) Combined isolated yields. d) Reaction was conducted in 1,4-dioxane under reflux. $e$ ) $o$-Ns=2-nitrophenylsulfonyl.

2,4-cis- and 2,4-trans-3-alkyl-2-alkenylazetidines $\mathbf{4 4 a}$ and $\mathbf{4 5}$ (82: 18; Table 2, entry 1), while in DMF, unexpectedly, 2,4cis-isomer 44a was afforded exclusively (entry 2). Similar results were obtained using other $\beta$-amino allenes 43 bearing a variety of alkyl (isobutyl, benzyl, siloxymethyl, or methoxycarbonylethyl group) and $N$-protecting groups (Mts, Ts, Mtr), yielding the 2,4-cis-4-alkyl-2-alkenylazetidines 44 in good to excellent yields. However, the amino allene 43d bearing a $o$-nitrophenylsulfonyl ( $o$-Ns) group gave a considerable amount of the six-membered ring 46 along with the desired azetidine 44d (44d : 46=62:38; entry 5), in analogy with the results by Hiemstra reported almost at the same time. ${ }^{56)}$ Other aryl- or alkenyl groups such as a 3-nitrophenyl, $(E)$ styryl, or 4-methylphenyl group can also be introduced on the double bond of the alkenylazetidines (entries 10-12).

Chart 8 shows a plausible pathway for the preferable for- mation of 2,4-cis-2-alkenylazetidine 44 over its 2,4-trans isomer 45. The two $\eta^{3}$-allylpalladium complexes 47 and 49 , which would be generated by the reaction of $\beta$-amino allene 43 with $\mathrm{R}-\mathrm{Pd}-\mathrm{X}$, are expected to be interconvertible via a $\eta^{3}-\eta^{1}-\eta^{3}$ mechanism. Since unfavorable steric interaction between the arylsulfonyl and allyl groups in $\mathbf{5 1}$ or arylsulfonyl and $\mathrm{R}^{1}$ groups in $\mathbf{5 2}$ would destabilize these conformers, predominant formation of 2,4-cis-azetidine 44 via the conformer $\mathbf{5 0}$ is readily understood. In addition, the predominant formation of 2,4-cis-azetidines would also be influenced by palladium $(0)$-catalyzed isomerization. ${ }^{69}$ )

3.2. Palladium(0)-Catalyzed Cyclization of Allenenes Including Tandem Cyclization ${ }^{70-72)}$ Allenes of general type 53, which bears a nucleophilic moiety such as a nitrogen or oxygen-containing functional group, are a well-known class of compounds that undergo a variety of palladium(0)- 


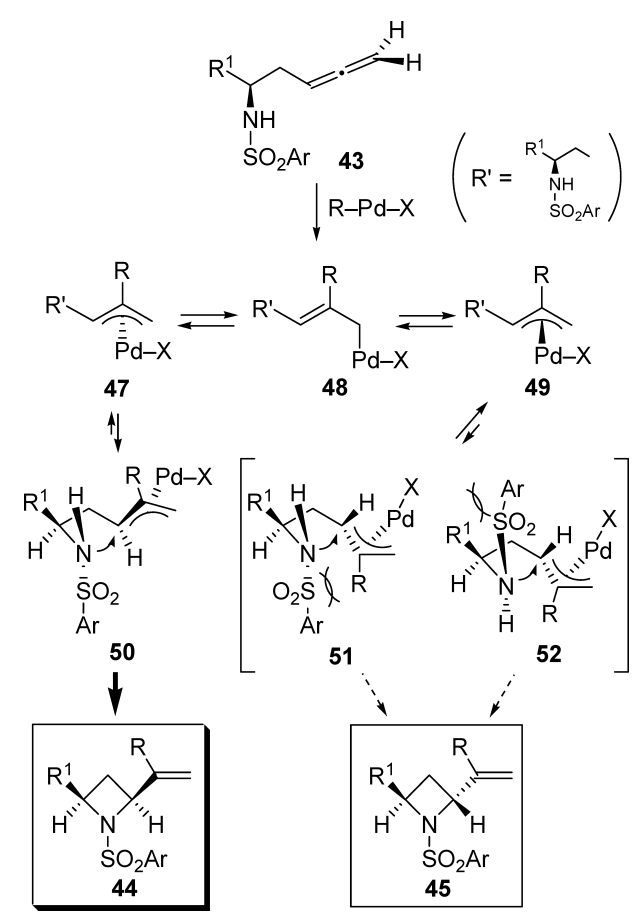

Chart 8. Palladium-Catalyzed Stereoselective Formation of 2,4-cis-Azetidine 44

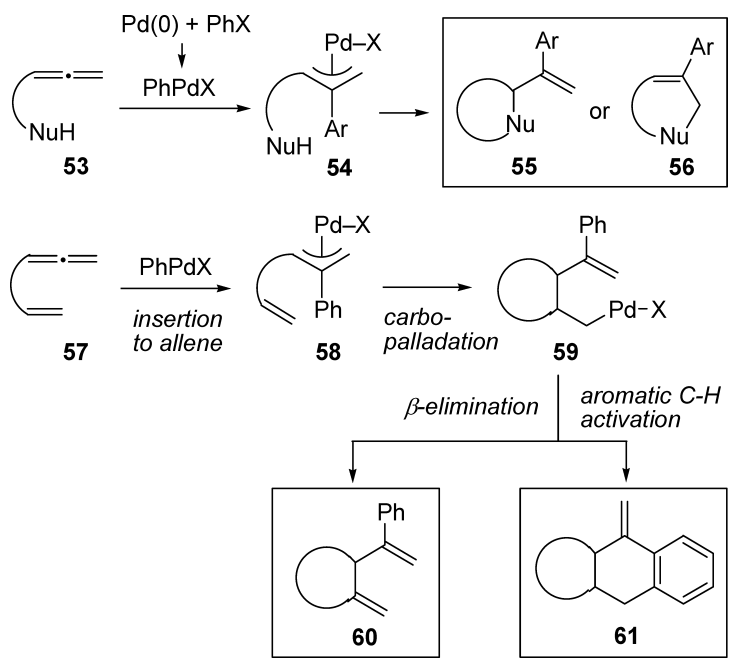

Chart 9. Palladium(0)-Catalyzed Cyclization of Allenes

catalyzed cyclizations to form cyclic products $\mathbf{5 5}$ or $\mathbf{5 6}$ (Chart 9). ${ }^{37-45)}$ In sharp contrast, however, palladium-catalyzed reactions of allenes that contain an additional multiple bond have scarcely been studied. Recently, cyclizations of bisallenes on treatment with silylstannane and palladium(0) were independently reported by two research groups. ${ }^{73,74)}$ Palladium(II)-catalyzed oxidative cyclization of allene-substituted alkenes and palladium(0)-catalyzed cyclization of allenes bearing an allyl ester moiety were reported by Bäckvall. ${ }^{75,76)} \mathrm{Oh}$ and co-workers reported cyclization of allenynes in the presence of a palladium catalyst and organic acid. ${ }^{77,78)}$ However, palladium(0)-catalyzed tandem cyclization of an allene that contains an additional multiple bond has scarcely been investigated. ${ }^{79,80)}$

In analogy with the reaction of the allenes 53, which terminates with the intramolecular nucleophilic attack of the
$\eta^{3}$-allylpalladium(II) intermediate by a nucleophile, the allenene $\mathbf{5 7}$ could undergo a tandem cyclization of the type shown in Chart 9 under similar conditions. Thus, the $\eta^{3}$-allylpalladium(II) intermediate $\mathbf{5 8}$, formed by the reaction of the allenene $\mathbf{5 7}$ with phenylpalladium(II) halide, would be converted into the intermediate $\mathbf{5 9}$ by carbocyclization. ${ }^{81,82)}$ If $\beta$-hydride elimination then predominated, a monocyclic product 60 would be produced. However, further cyclization onto the aromatic ring through $\mathrm{C}-\mathrm{H}$ activation would lead to a tricyclic product such as $\mathbf{6 1}$ in a single step.

Palladium-catalyzed $\mathrm{C}-\mathrm{H}$ activation of an aromatic group has received considerable attention in recent years. Particularly, tandem carbon-carbon bond formations through this process are useful in that complex molecules can be directly obtained in a single operation. Although palladium-catalyzed mono-cyclization onto an aryl ring forming two, ${ }^{83,84}$ ) three, ${ }^{85-87)}$ or four carbon-carbon bonds ${ }^{88,89)}$ in one-pot manner are well documented, the tandem reaction involving a bis-cyclization process is extremely rare..$^{90-93)}$ Tandem carbon-carbon bond formation including $\mathrm{C}-\mathrm{H}$ activation of aromatic rings using allenic compounds is unknown.

In an initial experiment, the palladium(0)-catalyzed cyclization of the allenene $\mathbf{6 2}-\mathbf{6 7}$ was investigated and found that the carbocyclization of allenenes and subsequent $\beta$-hydride elimination proceeds efficiently upon treatment with iodobenzene and $\mathrm{K}_{2} \mathrm{CO}_{3}$ in the presence of a catalytic amount of $\mathrm{Pd}\left(\mathrm{PPh}_{3}\right)_{4}$ (Table 3). Reaction of $\mathbf{6 2}$ in refluxing dioxane provided the 2,3-cis-pyrrolidine 68a in $60 \%$ yield as the sole isolable product (Table 3 , entry 1 ). Although the reaction in $\mathrm{CH}_{3} \mathrm{CN}$ gave a similar result, other polar solvents such as DMSO and DMF were less effective. The use of 4iodoanisole (entry 2) and 4-iodotoluene (entry 3) as the aryl halide gave comparable results to iodobenzene. The allenene 63 bearing an isobutyl group required prolonged reaction time for the complete consumption of the starting materials ( $24-30 \mathrm{~h}$, entries 4,5$)$. Therefore, the substituent $\alpha$ to the allene was found to be extremely important for the efficiency of the cyclization. The allenene $\mathbf{6 5}$, the amino group of which is protected by a Boc group, afforded $N$-Boc-pyrrolidine derivative 71 although in relatively low yield $(41 \%$, entry 7). A geminal dimethyl group of $\mathbf{6 6}$ assists the cyclization to 72 (entry 8); however, this reaction requires $20 \mathrm{~h}$ for the complete conversion. Internal allene $\mathbf{6 7}$ was also cyclized into the five-membered ring $\mathbf{7 3}$ in $59 \%$ yield. The observed (Z)-geometry of the double bond of 73 will be a consequence of thermodynamic preference for the $s y n-\eta^{3}$-allylpalladium(II) intermediate over other isomers. ${ }^{68)}$

In all cases examined, 2,3-trans-pyrrolidine could not be isolated from the reaction mixture. The observed 2,3-cis selectivity in the pyrrolidine formation can be rationalized as shown in Chart 10. Insertion of phenylpalladium iodide to the allenic moiety of $\mathbf{7 4}$ would give a $\eta^{3}$-allylpalladium(II) intermediate $\mathbf{7 5}$. If the intermediate $\mathbf{7 5}$ underwent carbocyclization via the conformation 76, the 2,3-trans-pyrrolidine 79 would be formed. However, an unfavorable steric interaction between pseudo-axial protons and the phenyl group in 76 does exist to destabilize this conformer. Thus, the ringformation would proceed preferentially from the more abundant conformers 77 and/or 78, and $\beta$-hydride elimination of the resulting alkylpalladium(II) yields the cis-pyrrolidine $\mathbf{8 0}$ as a single isomer. 
Table 3. Stereoselective Formation of Various 2,3-cis-Pyrrolidines ${ }^{a)}$

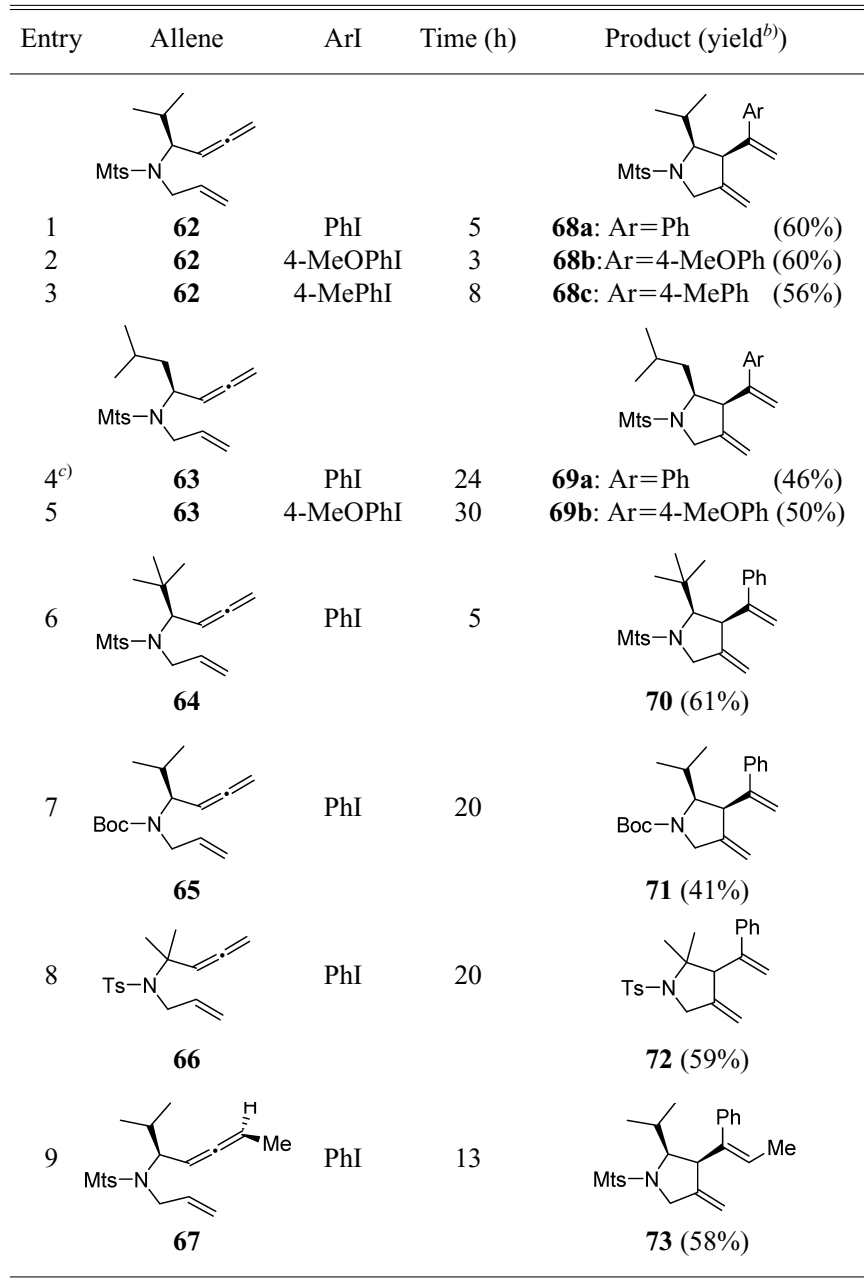

a) All reactions were carried out in the presence of $\mathrm{Pd}\left(\mathrm{PPh}_{3}\right)_{4}(10 \mathrm{~mol} \%), \mathrm{PhI}(2 \mathrm{eq})$ and $\mathrm{K}_{2} \mathrm{CO}_{3}$ (2 eq) in dioxane unless otherwise stated. b) Isolated yields. c) Increased amounts of $\operatorname{ArI}(4 \mathrm{eq})$ and $\mathrm{K}_{2} \mathrm{CO}_{3}(4 \mathrm{eq})$ were used.<smiles>[Z6]C(C=C=C)N(C)S(=O)(=O)c1ccccc1</smiles>

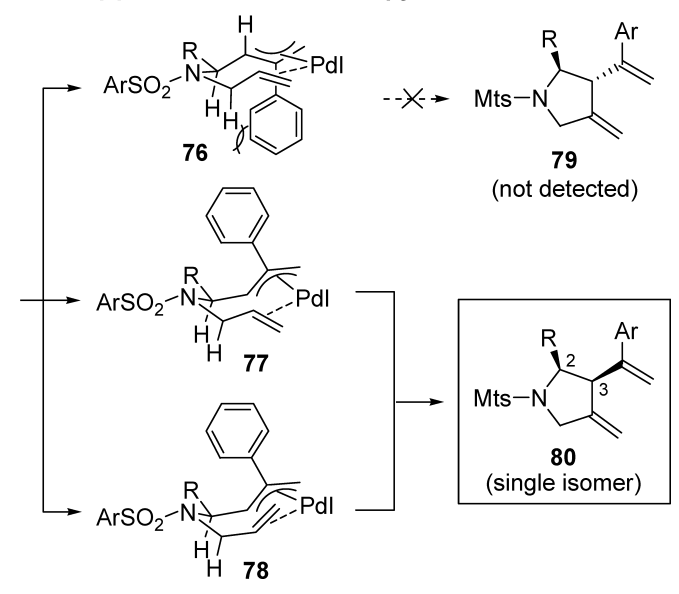

Chart 10. Stereoselective Formation of 2,3-cis-Pyrrolidines 80

Next, inhibition of the $\beta$-hydride elimination was investigated in order to promote the desired tandem cyclization. The author expected that the replacement of the $\beta$-hydrogen

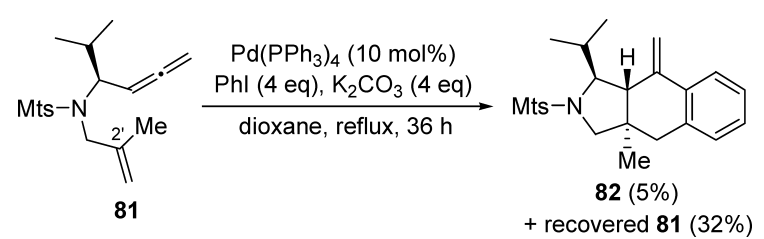

Chart 11. Palladium(0)-Catalyzed Tandem Cyclization of 2'-Methylated Allenene $\mathbf{8 1}$

atom with an alkyl group would suppress the $\beta$-hydride elimination and allow another cyclization step. However, introduction of a methyl group at the $2^{\prime}$-position dramatically decreased the reactivity of the allenene, and the desired tricyclic product $\mathbf{8 2}$ was obtained from the $2^{\prime}$-methylated allenene 81 in just 5\% yield after $36 \mathrm{~h}$ (Chart 11 ). However, this result clearly shows that inhibition of the $\beta$-hydride elimination does promote the desired tandem cyclization onto an aryl group by $\mathrm{C}-\mathrm{H}$ activation.

Next, the cyclization of allenenes $83-86$ bearing a phenyl substituent at the 3 '-position was investigated since the introduction of a substituent at the olefin terminus might impede the required arrangement of the palladium center relative to the hydrogen atom for $\beta$-hydride elimination to occur. ${ }^{94-96)}$ To the author's delight, the allenene $\mathbf{8 3}$ reacted with iodobenzene, $\mathrm{K}_{2} \mathrm{CO}_{3}$, and a catalytic amount of palladium( $(0)$ in dioxane to give a separable diastereomeric mixture of the benzoisoindole derivatives $\mathbf{8 8 a}$ and 89a in moderate yields $(41 \%, 10 \%$, respectively; Table 4 , entry 1$)$. This is the first example of a successful palladium(0)-catalyzed tandem cyclization of allenenes. Introduction of an electron-donating substituent such as methyl and methoxy group at the 4-position of iodobenzene increased the reaction rate and slightly improved the combined yields of the tricyclic products (entries 2, 3). However, the reaction with 2-iodoanisole (entry 4) gave lower yields of the desired benzoisoindoles 88d (36\%) and $89 \mathbf{d}(2 \%)$, presumably due to the steric hindrance of the 2-anisyl group. Similarly, other $N$-cinnamylamino allenes 84-86 also reacted to afford the expected tricyclic products (entries 5-7). Substituents other than a phenyl group at the olefin terminus can also promote the tandem cyclization (entries 8,9 ).

In order to examine the scope of the tandem cyclization as a useful synthetic method of various polycyclic compounds, the reaction of the $N$-cyclohexenyl derivatives 97 (Chart 12) was investigated. Treatment of 97 under the standard cyclization conditions led to formation of the desired tetracyclic compounds 98 in $49-61 \%$ yield as a single isomer. It is noteworthy that three stereogenic centers are newly created with complete stereoselectivity. These results clearly demonstrate the utility of this tandem cyclization as a novel method for the synthesis of complex heterocycles.

Three possible mechanistic pathways for the final $\mathrm{C}-\mathrm{H}$ activation are shown in Chart 13. (1) Intramolecular oxidative addition of an aromatic $\mathrm{C}-\mathrm{H}$ bond of 99 to palladium(II) to form palladium(IV) intermediate 100, ${ }^{97-99)}$ which gives the benzoisoindole $\mathbf{1 0 3}$ on loss of $\mathrm{HI}$ and subsequent reductive elimination (path A). (2) Carbopalladation onto the aryl group in 99 would give the palladium(II) intermediate 101, in which the $\beta$-hydrogen has an anti-configuration to the palladium atom. In most cases, the subsequent $\beta$-hydride elimination proceeds with the syn-stereochemistry. ${ }^{95,96)}$ Accord- 
Table 4. Palladium(0)-Catalyzed Tandem Cyclization of Allenenes with Iodobenzene Derivatives ${ }^{a}$

\begin{tabular}{|c|c|c|c|c|c|}
\hline Entry & Substrate & ArI & Reaction time (h) & \multicolumn{2}{|c|}{ Product $\left(\right.$ yield $\left.^{b)}\right)$} \\
\hline 1 & 83 & $\mathrm{PhI}$ & 7.5 & 88a: $R=H \quad \overline{P h} \quad(41 \%)$ & 89a: $R=H$ Pि \\
\hline 2 & & 4-MePhI & 7 & 88b: $\mathrm{R}=11-\mathrm{Me} \quad(37 \%)$ & 89b: $\mathrm{R}=\mathrm{Me}$ \\
\hline 3 & & 4-MeOPhI & 3.5 & 88c: $\mathrm{R}=11-\mathrm{OMe}(36 \%)$ & 89c: $\mathrm{R}=\mathrm{OMe} \quad(20 \%)$ \\
\hline 4 & & 2-MeOPhI & 10 & 88d: $\mathrm{R}=13-\mathrm{OMe}(36 \%)$ & 89d: $\mathrm{R}=13-\mathrm{OMe}(2 \%)$ \\
\hline $5^{c)}$ & 84 & $\mathrm{PhI}$ & 29 & $90(21 \%)$ & $91(14 \%)$ \\
\hline 6 & 85 & $\mathrm{PhI}$ & 23 & $92(30 \%)$ & $93(24 \%)$ \\
\hline 7 & 86 & $\mathrm{PhI}$ & 30 & $94(16 \%)$ & $95(35 \%)$ \\
\hline $\begin{array}{l}8^{c)} \\
9\end{array}$ & 87 & $\begin{array}{c}\mathrm{PhI} \\
\text { 4-MeOPhI }\end{array}$ & $\begin{array}{l}28 \\
30\end{array}$ & $\begin{array}{l}\text { 96a: } R=H \quad(42 \%) \\
96 b: R=O M e(45 \%)\end{array}$ & \\
\hline
\end{tabular}

a) Unless otherwise stated, reactions were carried out with $\mathrm{Pd}\left(\mathrm{PPh}_{3}\right)_{4}(10 \mathrm{~mol} \%)$, ArI (2 eq), and $\mathrm{K}_{2} \mathrm{CO}_{3}(2$ eq) in dioxane under reflux. b) Isolated yields. c) Increased amounts of $\operatorname{ArI}(4 \mathrm{eq})$ and $\mathrm{K}_{2} \mathrm{CO}_{3}(4 \mathrm{eq})$ were used.

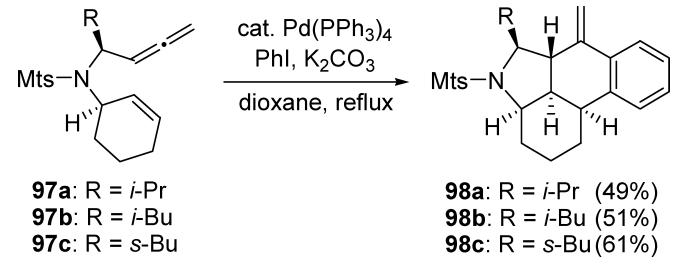

Chart 12. Palladium(0)-Catalyzed Tandem Cyclization of $\mathbf{9 7}$

ingly, the rearomatization to $\mathbf{1 0 3}$ might proceed through a facile stereomutation furnishing the required syn-elimination, ${ }^{100,101)}$ presumably by the $\eta^{3}-\eta^{1}-\eta^{3}$ mechanism of the allylpalladium(II) species. $^{102)}$ Also, the anti-elimination might be one rationalization for the rearomatization of 101. ${ }^{103-105)}$ Alternatively, (3) electrophilic attack of the aromatic carbon onto the palladium(II) intermediate 99 would give a cationic intermediate 102, deprotonation of which and subsequent reductive elimination would afford 103 (path C). ${ }^{106-108)}$ At the present stage of the author's understanding, it is difficult to determine which is the most favorable reaction course in this reaction, as well as in related reactions. ${ }^{109-112)}$

Finally, direct synthesis of tri- or tetracyclic heterocycles using the tandem cyclization with heteroaromatic halides was investigated (Table 5). The reaction of the allenene $\mathbf{8 3}$ with 2-bromothiophene yielded tricyclic products $\mathbf{1 0 4}$ in $59 \%$ combined isolated yields (entry 1 ). The cyclization using 3-

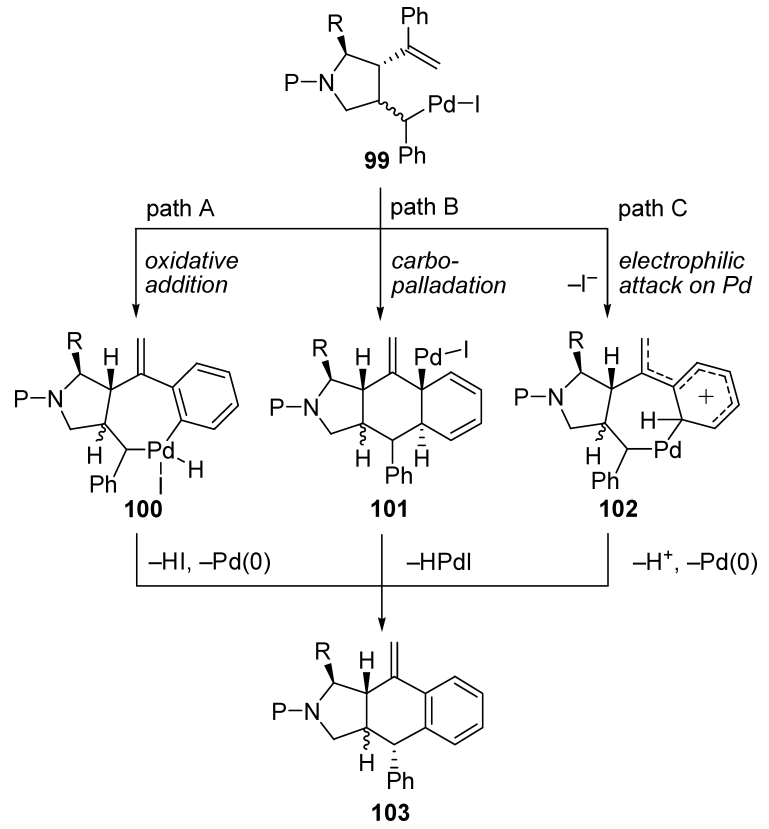

Chart 13. Possible Reaction Pathways for the $\mathrm{C}-\mathrm{H}$ Functionalization

bromofuran afforded tricyclic furan $\mathbf{1 0 5}$ as a single isolable diastereomer (entry 2). The relatively low yield (31\%) is due to instability of $\mathbf{1 0 5}$. Furthermore, it was found that bicyclic heteroaryl halides are good partners for the tandem cycliza- 
tion of the allenene $\mathbf{8 3}$ (entry 3). Although we suffered from lower reactivity of chloropyrazine in the reaction with $\mathbf{8 3}$, this problem has been overcome by using iodopyrazine (entry 4) to give $\mathbf{1 0 7}$ in $62 \%$ yield.

3.3. Novel Synthesis of 3-Azabicyclo[3.1.0]hexanes by Unusual Palladium(0)-Catalyzed Cyclopropanation of Allenenes ${ }^{71,113)}$ 3-Azabicyclo[3.1.0]hexane is a basic structure of biologically active natural products ${ }^{114)}$ such as CC1065, duocarmycin, and indolizomycin, and also a framework of a pharmacologically important class of compounds such as 3,4-methanoprolines, ${ }^{115,116)}$ poly-L-proline type II peptide mimetics, ${ }^{117)}$ and conformationally rigid analogues of [1,4'-bipiperidine]-4'-carboxamides (Fig. 2). ${ }^{118)}$ Moreover, heterocyclic compounds with this ring system are known as useful intermediates for cyclopropane amino acids such as

Table 5. Palladium(0)-Catalyzed Tandem Cyclization of Allenene $\mathbf{8 3}$ with Heteroaryl Halides ${ }^{a)}$

Entry Time (h) Product (yield)

a) All reactions were carried out using allenene $\mathbf{6 3}$ in the presence of $\mathrm{Pd}\left(\mathrm{PPh}_{3}\right)_{4}$ $(10 \mathrm{~mol} \%)$, ArI (2 eq), and $\mathrm{K}_{2} \mathrm{CO}_{3}(2 \mathrm{eq})$ in dioxane under reflux. b) Isolated yields. conformationally restricted analogues of L-glutamate ${ }^{119)}$ and $\gamma$-aminobutyric acid (GABA). ${ }^{120,121)}$ Therefore, stereoselective construction of a nonracemic 3-azabicyclo[3.1.0] hexane framework is an attractive research subject for organic chemists. However, catalytic synthesis of 3-azabicyclo[3.1.0] hexanes is relatively rare. ${ }^{122-126)}$

During the course of the study on tandem cyclization of allenenes (Section 3.2), it was found that 3-azabicyclo[3.1.0] hexanes can be directly constructed from allenenes by simply changing the reaction conditions (Table 6). Although the reaction of allenene $\mathbf{6 2}$ with allyl carbonate and catalytic $\mathrm{Pd}\left(\mathrm{PPh}_{3}\right)_{4}$ or $\left[\left(\eta^{3}-\mathrm{C}_{3} \mathrm{H}_{5}\right) \mathrm{PdCl}\right]_{2}$ in $\mathrm{CH}_{3} \mathrm{CN}$ led to recovery of the starting material, it was found that treatment of $\mathbf{6 2}$ with allyl carbonate in the presence of a catalytic amount of $\mathrm{Pd}_{2}(\mathrm{dba})_{3} \cdot \mathrm{HCl}_{3}$ in $\mathrm{CH}_{3} \mathrm{CN}$ at $80^{\circ} \mathrm{C}$ afforded 3-azabicyclo[3.1.0]hexane 111a in 64\% yield (entry 1). Although the

Table 6. Synthesis of 3-Azabicyclo[3.1.0]hexanes from Allenenes ${ }^{a}$ )

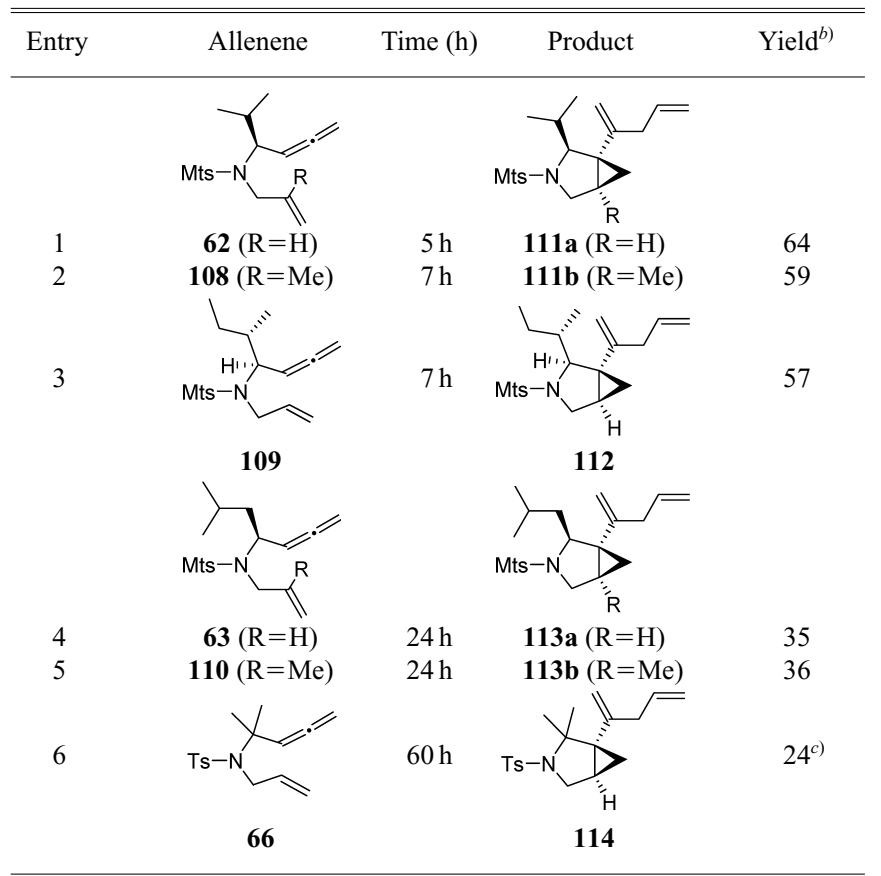

a) All reactions were carried out with $\mathrm{Pd}_{2}(\mathrm{dba})_{3} \cdot \mathrm{CHCl}_{3}(10 \mathrm{~mol} \%)$ and allyl carbonate $\left(6\right.$ eq) in $\mathrm{CH}_{3} \mathrm{CN}$. b) Isolated yields. c) The starting allenene 66 was recovered $(29 \%)$.<smiles></smiles>

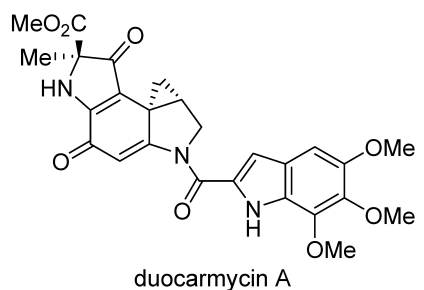

CC-1065<smiles>C/C=C(C)/C=C/C=C/C1C2CC2C2(O)C3OC3CCN12</smiles><smiles>O=C(O)C1CC2CC21</smiles>

cis-3,4-methanoproline

[1,4'-bipiperidine]-4'-caboxamide analogue

Fig. 2. Representative Pharmacologically Important Compounds Having a 3-Azabicyclo[3.1.0]hexane Framework 
formation of small rings, including cyclopropanes, ${ }^{58,59)}$ by intramolecular nucleophilic attack onto the allenic moiety is well documented, ${ }^{32-34,55-57)}$ direct synthesis of bicyclic cyclopropanes by the reaction of allenes with an additional multiple bond is unprecedented. Similarly, the reaction of allenenes 108 and 109 under the identical reaction conditions gave $111 \mathrm{~b}$ and 112 in $57-59 \%$ yields. In contrast, allenenes 63 and 110 having an isobutyl group (entries 4,5) and $\mathbf{6 6}$ having a geminal dimethyl group (entry 6) gave relatively low yields of the bicyclic cyclopropanes 113a, $\mathbf{b}$, and 114, respectively. These results clearly show that the presence of an appropriate sterically-congested substituent at the $\alpha$-position to the allenic moiety, which would assist and not interfere in the cyclization, is extremely important for the successful conversion. In fact, the corresponding allenene without the $\alpha$-substituent was completely inert to the reaction conditions. In all cases, a cyclized product of the type $\mathbf{8 0}$ (Chart 10) was not isolated, and the cyclopropanation reaction proceeded in a stereoselective manner.

Although the reaction mechanism of this cyclopropanation is not understood, this reaction clearly demonstrates a novel reactivity of allenes with a palladium( 0 ) catalyst. Chart 14 shows two explanations of the reaction leading to the bicyclic cyclopropanes 119. Reaction of allenene $\mathbf{1 1 5}$ with $\eta^{3}$-allylpalladium(II) methoxide, derived from allyl carbonate and palladium(0), gives the allylated $\eta^{3}$-allylpalladium(II) intermediate 116. If deprotonation of $\mathbf{1 1 6}$ predominates to form a palladium carbene intermediate $\mathbf{1 1 7}$ (path A), stereoselective formation of the cyclopropane $\mathbf{1 1 9}$ is readily understood. ${ }^{127)}$ However, to the best of the author's knowledge, generation of a palladium carbene species from $\eta^{3}$-allylpalladium(II) methoxide is unprecedented. If the intramolecular carbopalladation of 116 via 120 predominates (path B), alkylpalladium intermediate $\mathbf{1 2 1}$ would be formed. ${ }^{128)}$ Although isomerization of the double bond of $\mathbf{1 2 1}$ to $\mathbf{1 2 2}$ is necessary, this pathway also enables the stereoselective formation of bicyclic cyclopropane 119. The reason why the present reaction conditions promote the cyclopropanation reaction instead of the Oppolzer cyclization leading to $\mathbf{8 0}$ (Chart 10) is unclear.

\section{Cyclization of Bromoallenes}

4.1. A Highly cis-Selective Synthesis of 2-Ethynylaziridines by Intramolecular Amination of Chiral Bromoallenes ${ }^{129,130)}$ Reactions of bromoallenes have attracted much interest in recent years, because of their cumulated double bonds and high reactivity. ${ }^{131)}$ These reactions involve organocopper-mediated substitutions, ${ }^{132,133)}$ palladium-catalyzed cross-coupling reactions, ${ }^{134)}$ and the formation of nucleophilic allenylmetal reagents. ${ }^{135)}$ Among them, the organocopper-mediated substitution of bromoallenes is extremely useful in that the substitution of propargylic oxygen by an alkyl group can be carried out with overall retention of configuration ${ }^{136)}$ : both the bromination of propargyl esters with $\mathrm{CuBr} / \mathrm{LiBr}^{137,138)}$ and alkylation of the resulting bromoallenes by organocopper reagents proceed with inversion of configuration. ${ }^{139)}$ In contrast, the reaction of bromoallenes with nitrogen nucleophiles is relatively limited. Although the intermolecular amination of racemic bromoallenes has been already reported, ${ }^{140-142)}$ an intramolecular reaction and a stereochemical course of the amination toward chiral bro-
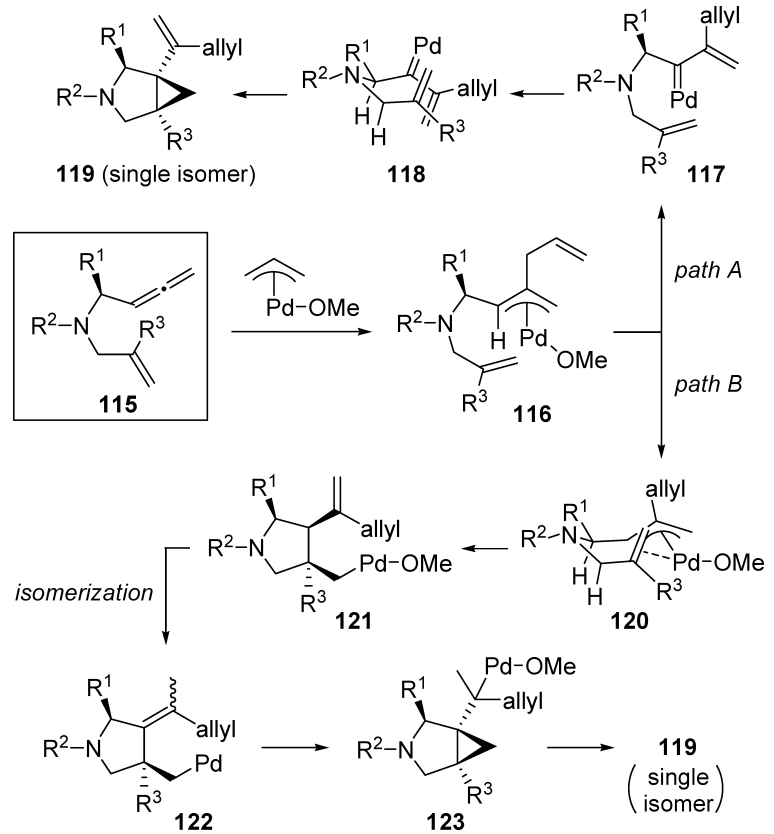

Chart 14. Explanations of the Cyclization of Allenenes Leading to the Bicyclic Cyclopropanes

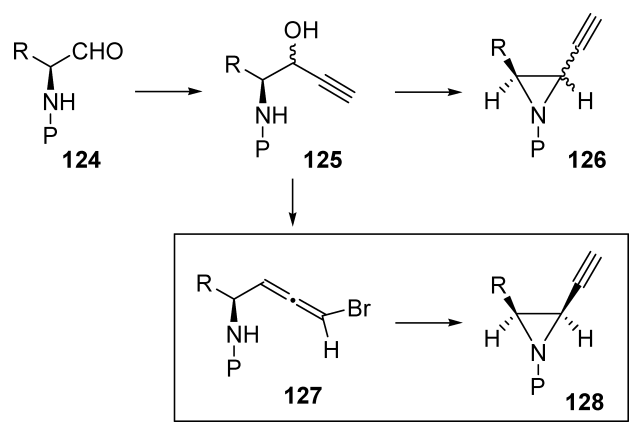

Chart 15. Aziridination of Bromoallenes

moallenes were unprecedented.

In connection with a research program directed toward the reactions of 2-ethynylaziridines both as carbon electrophiles (Section 2.1) ${ }^{11,12)}$ and nucleophiles, ${ }^{143,144)}$ our group required a reliable synthetic method of chiral 2-ethynylaziridines in a stereoselective manner. Ethynylaziridines can be synthesized by the reaction of $N$-tosylimines with sulfonium ylide, ${ }^{145)}$ reaction of lithium acetylides ${ }^{146)}$ or allenylzincs ${ }^{147)}$ with imines, or the Mitsunobu reaction of amino alcohols bearing an ethynyl group ${ }^{20)}$; however, the stereoselective synthesis of enantiopure 2-ethynylaziridines is still difficult. Apparently, one of the simplest methods for the synthesis of enantiopure ethynylaziridines $\mathbf{1 2 6}$ is the Mitsunobu reaction of the propargyl alcohol 125 (Chart 15), which in turn could be readily prepared from amino aldehydes $\mathbf{1 2 4}$ derived from $\alpha$ amino acids. However, a highly diastereoselective synthesis of either syn- or anti-125 by the reaction of amino aldehydes with metal acetylides has proven to be difficult, with the exception of some examples. ${ }^{148-150)}$ Since aziridination under the Mitsunobu conditions proceeds with inversion of configuration, a mixture of 2,3-cis- and 2,3-trans-2-ethynylaziridines $\mathbf{1 2 6}$ is always obtained from a diastereomixture of 125. 

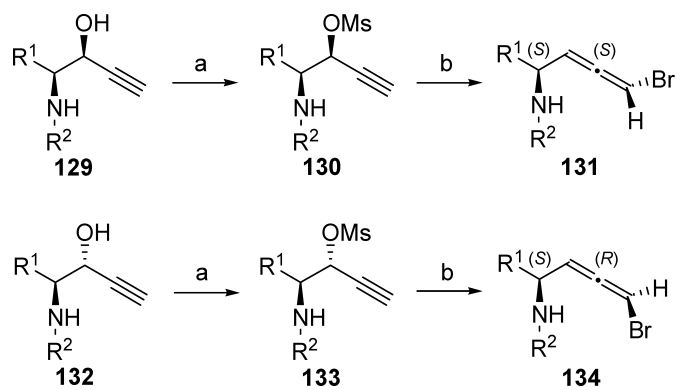

Reagents and Conditions: (a) $\mathrm{MsCl}, \mathrm{Et}_{3} \mathrm{~N}, \mathrm{THF},-78$ to $-40^{\circ} \mathrm{C}$; (b) $\mathrm{CuBr} \cdot \mathrm{DMS}$, $\mathrm{LiBr}$, THF, 25 or $50^{\circ} \mathrm{C}$.

Chart 16. Preparation of Bromoallenes Bearing a Protected Amino Group

Table 7. NaH-Mediated Aziridination of Bromoallenes in $\mathrm{DMF}^{a)}$

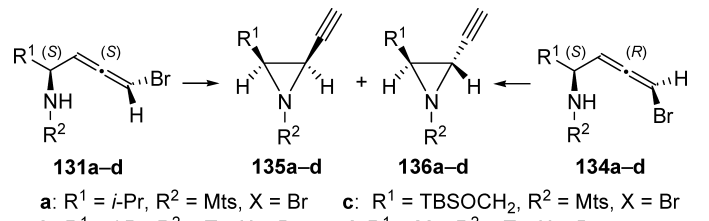

\begin{tabular}{|c|c|c|c|c|}
\hline Entry & Allene & Time (min) & $\begin{array}{c}\text { Ratio }^{b)} \\
\text { cis:trans }\end{array}$ & Yield $^{c)}$ \\
\hline 1 & 131a & 60 & $\mathbf{1 3 5} \mathbf{a}: \mathbf{1 3 6} \mathbf{a}=82: 18$ & $93 \%$ \\
\hline 2 & 131b & 60 & $\mathbf{1 3 5} \mathbf{b}: \mathbf{1 3 6} \mathbf{b}=88: 12$ & $99 \%$ \\
\hline 3 & 131c & 60 & $135 c: 136 c=79: 21$ & $76 \%$ \\
\hline 4 & $131 d^{d)}$ & 180 & 135d $: \mathbf{1 3 6} d=91: 9$ & $85 \%$ \\
\hline 5 & $134 a$ & 30 & $\mathbf{1 3 5 a}: \mathbf{1 3 6} \mathbf{a}=>99: 1$ & $99 \%$ \\
\hline 6 & $134 b$ & 30 & $\mathbf{1 3 5} \mathbf{b}: \mathbf{1 3 6} \mathbf{b}=>99: 1$ & $84 \%$ \\
\hline 7 & $134 c$ & $30^{e)}$ & $135 c: 136 c=92: 8$ & $91 \%$ \\
\hline 8 & $134 d^{d)}$ & 240 & 135d $: \mathbf{1 3 6} d=93: 7$ & $76 \%$ \\
\hline
\end{tabular}

b: $R^{1}=i-\operatorname{Pr}, R^{2}=T s, X=B r \quad$ d: $R^{1}=M e, R^{2}=T s, X=B r$

a) Reactions were carried out with $\mathrm{NaH}\left(1.2\right.$ or 1.3 eq) at $25^{\circ} \mathrm{C}$ in DMF unless oth erwise stated. b) Ratios were determined by ${ }^{1} \mathrm{H}-\mathrm{NMR}$ or isolation of the products. c) Combined isolated yields. d) Diastereomixture of the bromoallenes was used ( $96: 4$ for 131d and $97: 3$ for 134d). e) Reaction was conducted at $50^{\circ} \mathrm{C}$.

To establish a stereoselective synthetic method of chiral 2ethynylaziridines 126, the author planned an aziridination of bromoallenes 127 bearing a protected amino group, which would be readily prepared from the propargyl alcohol $\mathbf{1 2 5}$ (Chart 15). The ( $S$,aS)-bromoallenes 131 bearing a protected amino group were synthesized from syn-amino alcohols $\mathbf{1 2 9}^{151)}$ in high yields (Chart 16). Thus, mesylation of $\mathbf{1 2 9}$ by the standard method gave 130, which was then converted into the desired bromoallenes $\mathbf{1 3 1}$ by treatment with $\mathrm{CuBr} \cdot \mathrm{DMS} / \mathrm{LiBr}^{137,138)}$ Similarly, $(S, \mathrm{a} R)-\mathbf{1 3 4}$ were synthesized from the anti-amino alcohols $\mathbf{1 3 2} .^{151)}$

The intramolecular amination of the bromoallenes bearing an ( $N$-Boc)amino group showed poor stereoselectivities (cis: trans $=60: 40-41: 59$ ) under various reaction conditions. In contrast, the reaction of $N$-arylsulfonylated amino allenes showed good to high 2,3-cis selectivity. The results are summarized in Table 7 . NaH-mediated reaction of 131a in DMF afforded 2,3-cis-aziridines 135a in 82:18 ratio and high yield (93\%, entry 1$)$. Similarly, other $(S$, a $S)$-bromoallenes $\mathbf{1 3 1 b}$ - d yielded mixtures of 2,3-cis- and 2,3-trans-2ethynylaziridines in which the cis-isomers 135 predominated (79:21-91:9, entries 2-4). Interestingly, the highest 2,3cis selectivity was observed in the reaction of bromoallene 131d bearing the smallest substituent $\left(\mathrm{R}^{1}=\mathrm{Me}\right)$ at $\mathrm{C}-4$

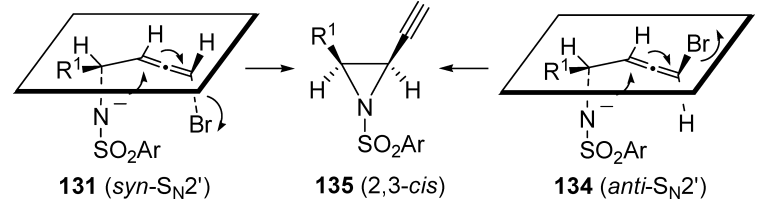

Chart 17. Stereochemical Course of the NaH-Mediated Aziridination of 131 and 134 in DMF

Table 8. NaH-Mediated Aziridination of Bromoallenes in $\mathrm{THF}^{a}$ )

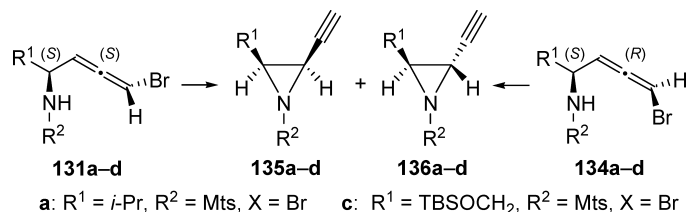

a: $\mathrm{R}^{1}=i-\mathrm{Pr}, \mathrm{R}^{2}=\mathrm{Mts}, \mathrm{X}=\mathrm{Br} \quad$ c: $\mathrm{R}^{1}=\mathrm{TBSOCH}_{2}, \mathrm{R}^{2}=\mathrm{Mts}, \mathrm{X}=\mathrm{Br}$ b: $\mathrm{R}^{1}=i-\mathrm{Pr}, \mathrm{R}^{2}=\mathrm{Ts}, \mathrm{X}=\mathrm{Br} \quad \mathrm{d}: \mathrm{R}^{1}=\mathrm{Me}, \mathrm{R}^{2}=\mathrm{Ts}, \mathrm{X}=\mathrm{Br}$

\begin{tabular}{ccccc}
\hline \hline Entry & Allene & Time $(\mathrm{h})$ & $\begin{array}{c}\text { Ratio }^{b)} \\
(\text { cis }: \text { trans })\end{array}$ & Yield $\left.^{c}\right)$ \\
\hline 1 & 131a & 4 & $\mathbf{1 3 5 a}: \mathbf{1 3 6 a}=>99: 1$ & $84 \%$ \\
2 & 131b & 17 & $\mathbf{1 3 5 b}: \mathbf{1 3 6}=>99: 1$ & $99 \%$ \\
3 & 131c & $5^{d)}$ & $\mathbf{1 3 5}: \mathbf{1 3 6}=>99: 1$ & $\left.48 \%{ }^{e}\right)$ \\
4 & 131d & 48 & $\mathbf{1 3 5 d}: \mathbf{1 3 6} \mathbf{d}=>99: 1$ & $77 \%$ \\
5 & 134a & $1^{d)}$ & $\mathbf{1 3 5 a}: \mathbf{1 3 6 a}=26: 74$ & $92 \%$
\end{tabular}

a) Reactions were carried out at $25^{\circ} \mathrm{C}$ using $\mathrm{NaH}$ ( 1.2 or $\left.1.3 \mathrm{eq}\right)$ in THF unless otherwise stated. b) Ratios were determined by ${ }^{1} \mathrm{H}-\mathrm{NMR}$ or isolation of the products. c) Combined isolated yields. d) The reaction was conducted at $50^{\circ} \mathrm{C}$. e) Desilylated bromoallene $(30 \%)$ was isolated.

(91:9, entry 4). Furthermore, upon the treatment of $(S, \mathrm{a} R)$ bromoallenes 134a-d with NaH/DMF (entries 5-8), 2,3cis-aziridines $\mathbf{1 3 5} \mathbf{a}-\mathbf{d}$ were obtained in higher selectivities (>92:8). When the allenes 134a and 134b bearing an isopropyl group were used (entries 5, 6), only the cis-isomers 135a and 135b were obtained. From these observations, the aziridination of the $(S, \mathrm{a} S)$-bromoallenes $\mathbf{1 3 1}$ with $\mathrm{NaH} / \mathrm{DMF}$ proceeds in a $s y n-S_{N} 2^{\prime}$ manner, while an anti-SN2' pathway predominates in the reaction of the $(S, \mathrm{a} R)$-allenes 134 (Chart 17). These results suggest that the described method would provide 2,3-cis-2-ethynylaziridines $\mathbf{1 2 8}$ stereoselectively from a mixture of syn- and anti-amino alcohols 125 (Chart 15).

These experimental results have been rationalized by the B3LYP density functional calculations together with the 6 $31+\mathrm{G}(\mathrm{d})$ basis set and the Onsager solvation model, conducted by Prof. Dr. Kaori Ando (University of Ryukyus). The transition structures for cis-aziridine formation of both $(4 S, \mathrm{a} R)$ - and $(4 S, \mathrm{a} S)$-bromoallenes in DMF are favored over the corresponding trans transition structures by 4.35 and $1.41 \mathrm{kcal} / \mathrm{mol}$, respectively. Furthermore, detailed analysis of the transition states in a gas phase predicted that a less polar solvent would give higher cis selectivities for $(4 S, \mathrm{a} S)$-bromoallenes. Accordingly, the reaction of $\mathbf{1 3 1}$ with $\mathrm{NaH}$ in a less polar solvent was next investigated. The results are summarized in Table 8. As expected, NaH-mediated cyclization of 131a in THF afforded only 2,3-cis-aziridine 135a as a single isomer (entry 1). Similarly, other $(S, a S)$-bromoallenes 131b - d gave satisfactory results (entries 2-4). A relatively low yield of the cis-aziridine 135c (48\%, entry 3$)$ in the reaction of the bromoallene 131c bearing a siloxymethyl group is due to the desilylation of 131c under the basic reaction conditions (30\% of the desilylated bromoallene was isolated). In 
sharp contrast, treatment of $(S, \mathrm{a} R)$-134a yielded the transaziridine 136 in moderate selectivity (entry 5). These results are in good agreement with the computational investigation by Prof. Ando. ${ }^{130)}$

4.2. Palladium(0)-Catalyzed Synthesis of MediumSized Heterocycles by Using Bromoallenes as Allyl Dication Equivalents ${ }^{152-154)}$ Medium-sized heterocycles are an extremely important class of compounds, the structural units of which are commonly found within the framework of a variety of natural products. ${ }^{155)}$ In particular, seven- and eightmembered heterocycles are constituents of a number of compounds with interesting pharmacological properties. ${ }^{156-160)}$ The abundance of medium rings bearing oxygen or nitrogen atom(s) in medicinally interesting compounds continues to ensure that they are important synthetic targets for organic chemists. Synthetic routes to medium-ring heterocycles involving direct ring closure are often slow and hampered by unfavorable enthalpies (the strain in many medium rings) and entropies (probability of the chain ends meeting) of the reaction. Today, the most powerful methodology for the synthesis of medium-sized rings is the ring-closing metathesis $(\mathrm{RCM})^{161)}$ that sometimes requires high dilution conditions for successful conversion and often involves generation of byproducts such as ethylene.

In the course of our examination of the aziridination reaction of bromoallenes (Section 4.1), ${ }^{129,130)}$ it was found that the reaction of bromoallene 131a with $\mathrm{Pd}\left(\mathrm{PPh}_{3}\right)_{4}$ and $\mathrm{NaOMe}$ in $\mathrm{MeOH}$ provided 2,3-cis-2-(1-methoxy)vinylaziridine 138 stereoselectively (Chart 18 ). This result strongly suggests the formation of $\eta^{3}$-allylpalladium complex 137 bearing a methoxy group on the central carbon. Namely, bromoallene 139 can act as an allyl dication equivalent 140 when treated with palladium(0) in an alcoholic solvent. Although similar types of reaction are often observed in propargylic carbonates with a palladium catalyst and soft nucleophiles such as active methylene, aryl alcohols or amide, ${ }^{162-166)}$ the reaction of allenic substrates and the synthesis of eight-membered rings are unprecedented.

Utilizing this chemistry, the author expected that various heterocyclic medium rings could be formed via intramolecular attack of an appropriate functionality such as an oxygen, a nitrogen or an active methylene nucleophile (Chart 19). If the intermolecular nucleophilic attack at the central carbon atom of the allene moiety of $\mathbf{1 4 1}$ predominates over the intramolecular reaction (path A), cyclized products 143 and/or 144 would be obtained. On the other hand, if the intramolecular nucleophilic attack takes place predominantly, cyclization at the central carbon atom of the allenic moiety would proceed to give 146 and/or 147.

According to the working hypothesis depicted in Chart 19, the synthesis of medium-sized heterocycles through the cyclization of bromoallenes in the presence of a palladium catalyst was investigated. To investigate the effect of the axial chirality on the cyclization reaction, diastereomerically pure bromoallenes were prepared. The results of the cyclization with bromoallenes 148-157 are summarized in Table 9 . Bromoallene 148, which bears an oxygen functionality, was treated with $\mathrm{NaOMe}(1.5 \mathrm{eq})$ in $\mathrm{MeOH}$ in the presence of $\mathrm{Pd}\left(\mathrm{PPh}_{3}\right)_{4}(5 \mathrm{~mol} \%)$ to afford the seven-membered ring 158 (61\%) along with its regioisomer $\mathbf{1 5 9}(28 \%$, entry 1$)$. In contrast, bromoallenes 149 with a bulkier substituent at C-4 gave

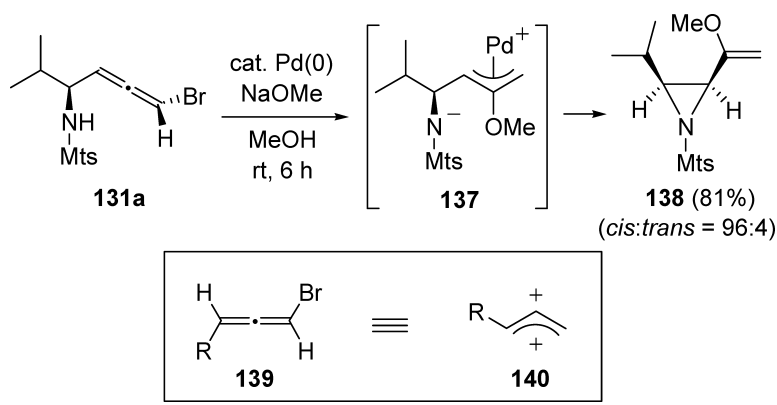

Chart 18. Bromoallenes as Allyl Dication Equivalents

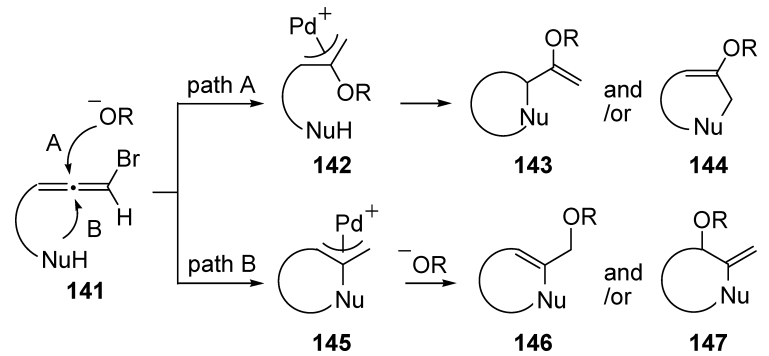

Chart 19. Regioselectivity of Palladium(0)-Catalyzed Cyclization of Bromoallenes

the seven-membered ring $\mathbf{1 6 0}$ as the only isolable isomers. These results clearly demonstrated that the regioselectivity of the second nucleophilic attack is controlled by the steric size of the substituent at C-4 of the bromoallenes. Other alcohols could be analogously used instead of $\mathrm{MeOH}$ for the present cyclization reaction. For example, bromoallene 150 was treated with a preformed mixture of $\mathrm{NaH}(1.5 \mathrm{eq})$ and BnOH-THF $(1: 3)$ in the presence of $\mathrm{Pd}\left(\mathrm{PPh}_{3}\right)_{4}(5 \mathrm{~mol} \%)$ to afford the tetrahydrooxepine derivative $\mathbf{1 6 1}$ having a benzyloxy group (72\%). Next, similar reactions were conducted with bromoallenes 151 and 152 (entries 4, 5), which bears a five-atom tether between the allenyl and hydroxyl groups. The reaction of these bromoallenes gave the eight-membered rings 162 and 163 as the sole isolable isomers. Furthermore, bromoallenes 153 with a nitrogen functionality, also gave the corresponding eight-membered ring $\mathbf{1 6 4}$ as a single isomer (entry 6).

The synthesis of benzo-annulated medium-sized heterocycles, which are the basic structures of pharmacologically important compounds, ${ }^{167)}$ was next investigated. The palladium(0)-catalyzed cyclization of bromoallene 154 in $\mathrm{MeOH}$ gave benzo $[b]-1,5$-oxazocine $\mathbf{1 6 5}$ in low yield (15\%). In contrast, when the reaction was conducted in a mixed solvent of $\mathrm{MeOH} / \mathrm{THF}(1: 1)$, the cyclized product $\mathbf{1 6 5}$ was obtained in a better yield (57\%; entry 7). Similarly, the reaction of the bromoallene 155 gave benzo[c]-1,5-oxazocine 166 under the same reaction conditions in high yield (82\%; entry 8$)$. Interestingly, when the amino allene 156 was used (entry 9), a methoxylated benzo[d]azocine derivative 167 was obtained as a major product ( $60 \%$ yield) along with a small amount of $\beta$-elimination product 168 (5\% yield), which was formed by $\beta$-hydride elimination of the $\eta^{3}$-allylpalladium(II) intermediate of the type 145 (Chart 19). This is presumably due to the relatively acidic nature of the $\beta$-hydrogen at the benzylic position.

In sharp contrast to the reaction of the bromoallenes hav- 
Table 9. NaH-Mediated Aziridination of Bromoallenes in $\mathrm{THF}^{a)}$

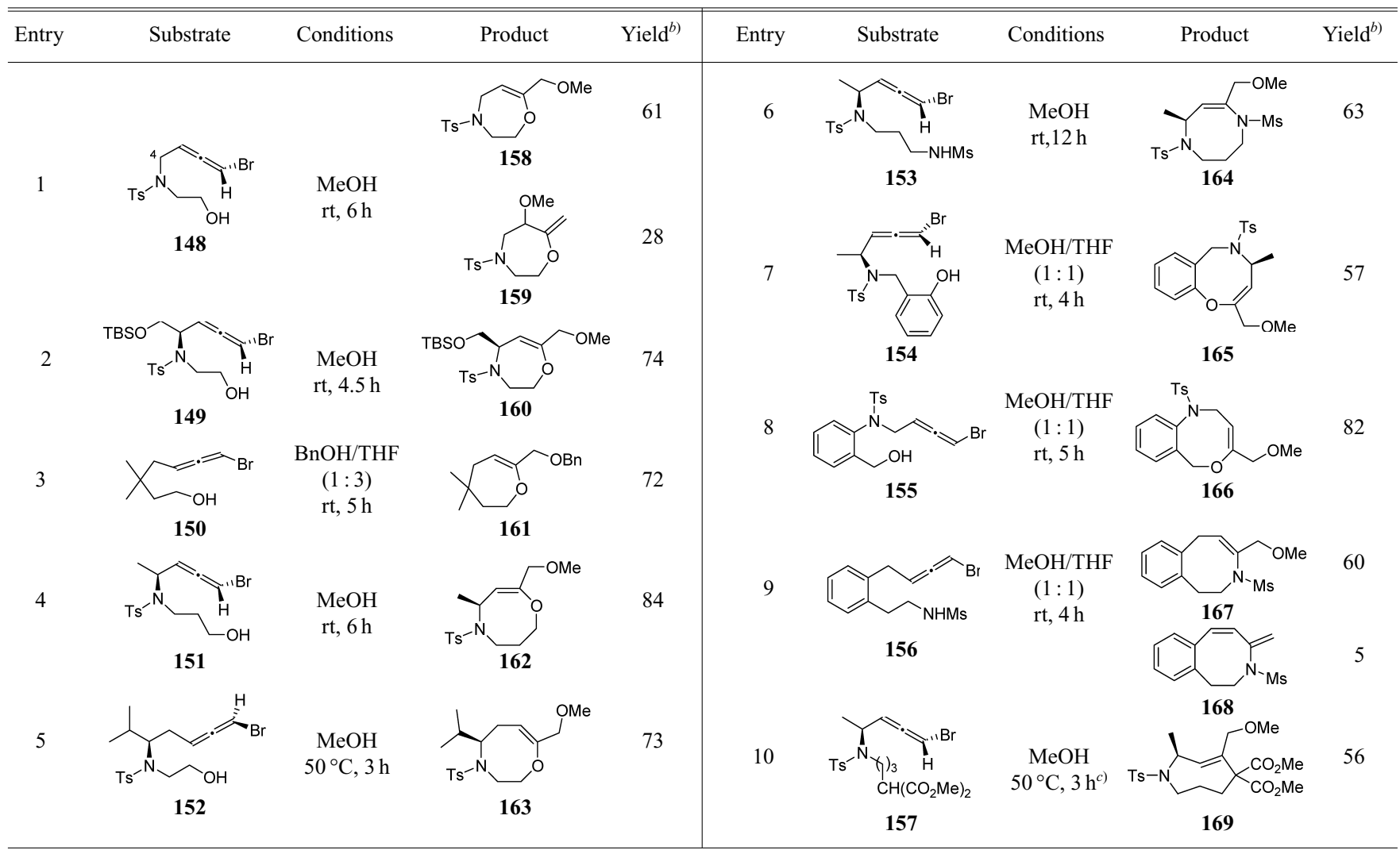

a) Reactions were carried out at with diastereomerically pure bromoallenes, $\mathrm{Pd}\left(\mathrm{PPh}_{3}\right)_{4}(5-10 \mathrm{~mol} \%)$, and $\mathrm{NaOMe}$ or $\mathrm{NaH}(1.5$ eq) unless otherwise stated. b) Isolated yields. c) $20 \mathrm{~mol} \%$ of $\mathrm{Pd}\left(\mathrm{PPh}_{3}\right)_{4}$ was used.

ing an oxygen or nitrogen nucleophile affording cis-rings exclusively, bromoallene $\mathbf{1 5 7}$ having an active methylene nucleophile gave eight-membered rings $\mathbf{1 6 9}$ with trans-configuration (56\% yield, entry 10$){ }^{168)}$ This allene is found to be less reactive than those having an oxygen or nitrogen nucleophile, presumably due to the steric hindrance. The results shown in Table 9 revealed that the intramolecular nucleophilic attack takes place at the central position of the allenic moiety (path $\mathrm{B}$ in Chart 19) and, in most cases, the regioselectivity of the attack of methoxide is extremely high. It should be clearly noted that both the $(S, \mathrm{a} S)$ - and $(S, \mathrm{a} R)$-bromoallenes equally undergo the present transformation to give the same products, which means that a diastereomeric mixture of bromoallenes can be directly employed for preparative use.

A possible reaction course is shown in Chart 20. Oxidative addition of bromoallene $\mathbf{1 7 0}$ to $\operatorname{Pd}(0)$ gives $\eta^{1}$-allenylpalladium complex 171, which is in a state of equilibrium with $\eta^{3}$-propargylpalladium complex $\mathbf{1 7 2 .}{ }^{169,170)}$ The first intramolecular nucleophilic addition occurs to the central carbon of $\eta^{3}$-propargylpalladium complex 172 to produce a palladacyclobutene 173. ${ }^{171)}$ This is followed by protonation by $\mathrm{MeOH}$ to generate $\eta^{3}$-allylpalladium complex 174. In many cases, the methoxide attacks the terminal carbon to give $\mathbf{1 7 5}$ because of the steric repulsion with the $\mathrm{R}$ substituent. When the $\mathrm{R}$ substituent is effectively smaller, a considerable amount of the adduct $\mathbf{1 7 6}$ is obtained by the attack of methoxide to the internal carbon of $\eta^{3}$-allylpalladium complex 174. Kurosawa, Ogoshi, and co-workers recently reported that a polar solvent shifts the equilibrium between $\eta^{1}$ allenyl- and $\eta^{3}$-propargylpalladium complexes toward the

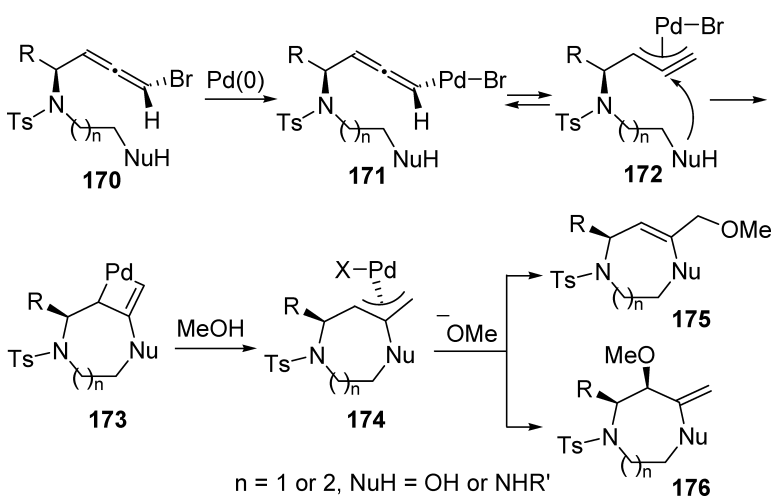

Chart 20. Possible Reaction Course

latter which is a reactive intermediate for the central attack. ${ }^{172,173)}$ Although the exact reason for the observed central attack in the presence of a monodentate ligand and an alcohol is unclear, the polar alcoholic solvent might promote the central attack by shifting the equilibrium toward the $\eta^{3}$ propargylpalladium complex 172. An alcoholic solvent will also promote the reaction by protonation of the palladacyclobutene intermediate $\mathbf{1 7 3}$.

\section{Conclusion}

As presented here, our group have developed several useful transformations of allenic substrates mainly for the synthesis of heterocyclic compounds including aziridines, azetidines, pyrrolidines, benzoisoindoles, 3-azabicyclo[3.1.0]hexanes, and various medium-sized heterocycles. Dur- 
ing the course of this study, our group have established two reliable synthetic methods of allenes. Although space restriction does not permit a detailed description, our group developed some other interesting novel reactions such as (1) stereoselective synthesis of 1,3-amino alcohols via allenylindium reagents using 2-ethynylaziridines as chiral carbon nucleophiles, ${ }^{143,144)}$ (2) samarium(II)-mediated radical cyclization onto an aromatic group, ${ }^{174-178)}$ (3) synthesis and isomerization of vinylaziridines and their application to the stereoselective synthesis of $(E)$-alkene dipeptide isosteres. ${ }^{64-67,179,180)}$ The author hopes the presented reactions based on the novel reactivities of allenes will facilitate further development of allene chemistry ${ }^{181-183)}$ and application to synthesis of pharmacologically important compounds from this class of compounds.

Acknowledgments First of all, the author would like to express his sincere respect and gratitude to Prof. Tetsuaki Tanaka, Graduate School of Pharmaceutical Sciences, Osaka University, for his kind and pertinent advice and encouragement during these studies. This research was possible only through the efforts and enthusiasm of Dr. H. Hamaguchi, T. Mizutani, K. Miyamura, Y. Takeoka, S. Kosaka, Y. Kadoh, and M. Ohata, Graduate School of Pharmaceutical Sciences, Osaka University, and A. Toda and M. Anzai, Graduate School of Pharmaceutical Sciences, Kyoto University. Thanks are also due to Prof. K. Ando, College of Education, University of Ryukyus, for her computational investigation and valuable discussion and prediction on the study of aziridination of bromoallenes. Parts of the work described were financially supported by a Grant-in-Aid for Encouragement of Young Scientists from the Ministry of Education, Culture, Sports, Science and Technology of Japan, Research Fellowships of the Japan Society for the Promotion of Science (JSPS) for Young Scientists, the Sasakawa Scientific Research Grant from the Japan Science Society, and Mitsubishi Chemical Corporation Fund, which are gratefully acknowledged. Finally, the author would like to express his heartfelt appreciation to the late Prof. Toshiro Ibuka, Graduate School of Pharmaceutical Sciences, Kyoto University, for his kind and valuable guidance and constant encouragement during the author's doctoral study.

\section{References and Notes}

1) Present address: Graduate School of Pharmaceutical Sciences, Kyoto University; Sakyo-ku, Kyoto 606-8501, Japan.

2) Patai S. (ed.), "The Chemistry of Ketenes, Allenes, and Related Compounds," John Wiley \& Sons, Chichester, 1980.

3) Brandsma L., Verkruijsse H. D., "Synthesis of Acetylenes, Allenes, and Cumulenes," Elsevier, Amsterdam, 1981.

4) Landor S. R. (ed.), "The Chemistry of the Allenes," Academic Press, London, 1982

5) Schuster H., Coppola G., "Allenes in Organic Synthesis," John Wiley \& Sons, New York, 1984.

6) Pasto D. J., Tetrahedron, 40, 2805-2827 (1984).

7) For a recent review, see: Krause N., Hashmi A. S. K. (ed.), "Modern Allene Chemistry," Wiley-VCH, Weinheim, 2004

8) For a recent review, see: Zimmer R., Dinesh C. U., Nandanan E., Khan F. A., Chem. Rev., 100, 3067-3125 (2000).

9) For a recent review, see: Hashmi A. S. K., Angew. Chem., Int. Ed., 39 $3590-3593$ (2000).

10) For a recent review, see: Yamamoto Y., Radhakrishnan U., Chem. Soc. Rev., 28, 199-207 (1999).

11) Ohno H., Toda A., Miwa Y., Taga T., Fujii N., Ibuka T., Tetrahedron Lett., 40, 349-352 (1999).

12) Ohno H., Toda A., Fujii N., Takemoto Y., Tanaka T., Ibuka T., Tetrahedron, 56, 2811-2820 (2000).

13) For a recent review on the synthesis of allenes see: Ohno H., Nagaoka Y., Tomioka K., "Modern Allene Chemistry," Vol. 1, ed. by Krause N., Hashmi A. S. K., Wiley-VCH, Weinheim, 2004, pp. $141-181$.

14) Lipshutz B. H., Sengupta S., "Organic Reactions," Vol. 42, ed. by Paquette L. O., John Wiley \& Sons, New York, 1992, p. 135.

15) Ibuka T., Yamamoto Y., "Organocopper Reagents," ed. by Taylor R. J. K., Oxford University Press, London, 1994, pp. 143-158.

16) Oehlschlager A. C., Czyzewska E., Tetrahedron Lett., 24, 5587-
5590 (1983)

17) Alexakis A., Marek I., Mangeney P., Normant J. F., Tetrahedron Lett., 30, 2387-2390 (1989).

18) Alexakis A., Marek I., Mangeney P., Normant J. F., Tetrahedron, 47, 1677-1696 (1991).

19) Ohno H., Toda A., Fujii N., Ibuka T., Tetrahedron: Asymmetry, 9, 3929-3933 (1998).

20) Ohno H., Toda A., Takemoto Y., Fujii N., Ibuka T., J. Chem. Soc., Perkin Trans. 1, 1999, 2949-2962 (1999).

21) Ohno H., Toda A., Oishi S., Tanaka T., Takemoto Y., Fujii N., Ibuka T., Tetrahedron Lett., 41, 5131-5134 (2000).

22) Ohno H., Miyamura K., Tanaka T., Oishi S., Toda A., Takemoto Y., Fujii N., Ibuka T., J. Org. Chem., 67, 1359-1367 (2002).

23) Lukas J., Visser J. P., Kouwenhoven A. P., J. Organomet. Chem., 50, 349-351 (1973).

24) Lupin M. S., Powell J., Shaw B. L., J. Chem. Soc. (A), 1966, $1687-$ 1691 (1966).

25) Semmelhack M. F., Brickner S. J., J. Am. Chem. Soc., 103, 39453947 (1981).

26) Searles S., Li Y., Nassim B., Lopes M.-T. R., Tran P. T., Crabbé P., J. Chem. Soc. Perkin Trans. 1, 1984, 747-751 (1984).

27) Myers A. G., Zheng B., J. Am. Chem. Soc., 118, $4492-4493$ (1996).

28) Dunn M. J., Jackson R. F. W., Pietruszka J., Turner D., J. Org. Chem., 60, 2210-2215 (1995).

29) For a recent review, see: Knochel P., Almene Perea J. J., Jones P., Tetrahedron, 54, 8275-8319 (1998).

30) For a recent example, see: Tamaru Y., Tanaka A., Yasui K., Goto S., Tanaka S., Angew. Chem., Int. Ed., 34, 787-789 (1995).

31) For a recent example, see: Sakamoto T., Takahashi K., Yamazaki T., Kitazume T., J. Org. Chem., 64, 9467-9474 (1999).

32) Ohno H., Toda A., Miwa Y., Taga T., Fujii N., Ibuka T., J. Org. Chem., 64, 2992-2993 (1999).

33) Anzai M., Toda A., Ohno H., Takemoto Y., Fujii N., Ibuka T., Tetrahedron Lett., 40, 7393-7397 (1999).

34) Ohno H., Anzai M., Toda A., Ohishi S., Fujii N., Tanaka T., Takemoto Y., Ibuka T., J. Org. Chem., 66, 4904-4914 (2001).

35) For a recent review, see: Bates R. W., Satcharoen V., Chem. Soc. Rev., 31, 12-21 (2002).

36) For a recent review, see: Ohno H., Yakugaku Zasshi, 121, 733-741 (2001).

37) Lathbury D., Vernon P., Gallagher T., Tetrahedron Lett., 27, 60096012 (1986).

38) Larock R. C., Berrios-Peña N. G., Fried C. A., J. Org. Chem., 56, 2615-2617 (1991).

39) Davies I. W., Scopes D. I. C., Gallagher T., Synlett, 1993, 85-87 (1993).

40) Kimura M., Tanaka S., Tamaru Y., J. Org. Chem., 60, 3764-3772 (1995).

41) Larock R. C., Zenner J. M., J. Org. Chem., 60, 482-483 (1995).

42) Karstens W. F. J., Rutjes F. P. J. T., Hiemstra H., Tetrahedron Lett., 38, 6275-6278 (1997).

43) Meguro M., Yamamoto Y., Tetrahedron Lett., 39, 5421-5424 (1998).

44) Grigg R., MacLachlan W. S., MacPherson D. T., Sridharan V., Suganthan S., Thornton-Pett M., Zhang J., Tetrahedron, 56, 6585-6594 (2000).

45) Kang S.-K., Kim K.-J., Org. Lett., 3, 511-514 (2001).

46) Claesson A., Sahlberg C., Luthman K., Acta Chem. Scand., B33, 309-310 (1979).

47) Kinsman R., Lathbury D., Vernon P., Gallagher T., J. Chem. Soc., Chem. Commun., 1987, 243-244 (1987).

48) Prasad J. S., Liebeskind L. S., Tetrahedron Lett., 29, 4253-4256 (1988).

49) Fox D. N. A., Lathbury D., Mahon M. F., Molloy K. C., Gallagher T., J. Chem. Soc., Chem. Commun., 1989, 1073-1075 (1989).

50) Kimura M., Tanaka S., Tamaru Y., Bull. Chem. Soc. Jpn., 68, 16891705 (1995)

51) Arredondo V. M., Tian S., McDonald F. E., Marks T. J., J. Am. Chem. Soc., 121, 3633-3639 (1999).

52) Arseniyadis S., Sartoretti J., Tetrahedron Lett., 26, 729-732 (1985).

53) Fox D. N. A., Lathbury D., Mahon M. F., Molloy K. C., Gallagher T., J. Am. Chem. Soc., 113, 2652-2656 (1991).

54) Ha J. D., Cha J. K., J. Am. Chem. Soc., 121, $10012-10020$ (1999).

55) Kang S.-K., Baik T.-G., Kulak A. N., Synlett, 1999, 324-326 
(1999).

56) Rutjes F. P. J. T., Tjen K. C. M. F., Wolf L. B., Karstens W. F. J., Schoemaker H. E., Hiemstra H., Org. Lett., 1, 717-720 (1999).

57) For a related epoxidation, see: Ma S., Zhao S., J. Am. Chem. Soc., 121, 7943-7944 (1999).

58) For a related cyclopropanation, see: Ma S., Zhao S., Org. Lett., 2, 2495-2497 (2000).

59) For a related cyclopropanation, see: Ma S., Jiao N., Zhao S., Hou J., J. Org. Chem., 67, 2837-2847 (2002).

60) For a recent review, see: Tanner D., Angew. Chem., Int. Ed. Engl., 33, 599-619 (1994).

61) For a recent review, see: Osborn H. M. I., Sweeney J., Tetrahedon: Asymmetry, 8, 1693-1715 (1997).

62) For a recent review, see: Ibuka T., Chem. Soc. Rev., 27, 145-154 (1998).

63) For a recent review, see: Ohno H., "Aziridines and Epoxides in Organic Synthesis," ed. by Yudin A., Wiley-VCH, Weinheim, 2005, in press.

64) Ibuka T., Mimura N., Aoyama H., Akaji M., Ohno H., Miwa Y., Taga T., Nakai K., Tamamura H., Fujii N., Yamamoto Y., J. Org. Chem., 62, 999-1015 (1997).

65) Ibuka T., Mimura N., Ohno H., Nakai K., Akaji M., Habashita H., Tamamura H., Miwa Y., Taga T., Fujii N., Yamamoto Y., J. Org. Chem., 62, 2982-2991 (1997)

66) Ohno H., Toda A., Fujii N., Miwa Y., Taga T., Yamaoka Y., Osawa E., Ibuka T., Tetrahedron Lett., 40, 1331-1334 (1999).

67) Ohno H., Takemoto Y., Fujii N., Tanaka T., Ibuka T., Chem. Pharm. Bull., 52, 111-119 (2004).

68) It is known that $s y n-\eta^{3}$-allylpalladium complexes are relatively more stable than other isomers, even if the central carbon of the allyl group is substituted by an aryl group. For example, see ref. 8 .

69) Upon exposure of a diastereomixture of $44 \mathrm{~b}$ and $45 \mathrm{~b}(44 \mathrm{~b}: \mathbf{4 5} \mathrm{b}=$ $10: 90)$ to the cyclization conditions at $70^{\circ} \mathrm{C}$ for $4 \mathrm{~h}$, an isomerized mixture was obtained in $53 \%$ yield $(\mathbf{4 4 b}: \mathbf{4 5 b}=60: 40)$. However, this palladium-catalyzed isomerization cannot explain the observed cis selectivity in DMF $(\mathbf{4 4}: \mathbf{4 5}=100: 1)$.

70) Ohno H., Miyamura K., Takeoka Y., Tanaka T., Angew. Chem., Int. Ed., 42, 2647-2650 (2003).

71) Ohno H., Takeoka Y., Kadoh Y., Miyamura K., Tanaka T., J. Org. Chem., 69, 4541-4544 (2004).

72) Ohno H., Miyamura K., Mizutani T., Kadoh Y., Takeoka Y., Hamaguchi H., Tanaka T., Chem. Eur. J., 11, 3728-3741 (2005).

73) Kang S.-K., Baik T.-G., Kulak A. N., Ha Y.-H., Lim Y., Park J., J. Am. Chem. Soc., 122, 11529-11530 (2000).

74) Shin S., RajanBabu T. V., J. Am. Chem. Soc., 123, 8416-8417 (2001).

75) Löfstedt J., Franzén J., Bäckvall J.-E., J. Org. Chem., 66, 8015-8025 (2001).

76) Franzén J., Löfstedt J., Dorange I., Bäckvall J.-E., J. Am. Chem. Soc., 124, 11246-11247 (2002).

77) Oh C. H., Jung S. H., Rhim C. Y., Tetrahedron Lett., 42, 8669-8671 (2001).

78) Oh C. H., Jung S. H., Park D. I., Choi J. H., Tetrahedron Lett., 45, 2499-2502 (2004).

79) A palladium(II)-catalyzed domino cyclization of allenynes in the presence of $\mathrm{LiBr}$ under oxygen at atmospheric pressure was recently reported: Alcaide B., Almendros P., Aragoncillo C., Chem. Eur. J., 8 , 1719-1729 (2002).

80) Yamamoto and co-workers reported that palladium-catalyzed carbonylative tandem cyclization of an allenene that contains an allyl acetate moiety in the presence of carbon monoxide afforded tetracyclic product in $22 \%$ yield, although it is only an isolated example: Doi T., Yanagisawa A., Nakanishi S., Yamamoto K., Takahashi T., J. Org. Chem., 61, 2602-2603 (1996).

81) For excellent reviews on related palladium-catalyzed carbocyclizations, see: Oppolzer W., Angew. Chem., Int. Ed., 28, 38-52 (1989).

82) For an excellent review on related palladium-catalyzed carbocyclizations, see: Negishi E., Copéret C., Ma S., Liou S.-Y., Liu F., Chem. Rev., 96, 365-393 (1996).

83) Larock R. C., Tian Q., J. Org. Chem., 63, 2002-2009 (1998).

84) Tian Q., Larock R. C., Org. Lett., 2, 3329-3332 (2000).

85) Catellani M., Chiusoli G. P., J. Organomet. Chem., 286, C13-C16 (1985).

86) Dyker G., Angew. Chem., Int. Ed. Engl., 31, 1023-1025 (1992).
87) Catellani M., Frignani F., Rangoni A., Angew. Chem., Int. Ed. Engl., 36, 119-122 (1997).

88) Reiser O., Weber M., de Meijere A., Angew. Chem., Int. Ed. Engl., 28, 1037-1038 (1989).

89) Mauleón P., Núñez A. A., Alonso I., Carretero J. C., Chem. Eur. J., 9 , $1511-1520$ (2003)

90) Grigg R., Fretwell P., Meerholtz C., Sridharan V., Tetrahedron, 50, 359-370 (1994)

91) Brown D., Grigg R., Sridharan V., Tambyrajah V., Tetrahedron Lett., 36, 8137-8140 (1995).

92) Grigg R., Loganathan V., Sridharan V., Tetrahedron Lett., 37, 33993402 (1996).

93) Teply F., Stará I. G., Stary I., Kollárovic A., Saman D., Fiedler P., Tetrahedron, 58, 9007-9018 (2002).

94) Heck R. F., Acc. Chem. Res., 12, 146-151 (1979).

95) Although the syn- $\beta$-elimination generally predominates, a base-induced anti elimination by an $\mathrm{E}_{2}$ mechanism can occur in limited cases. See, for examples: Takacs J. M., Lawson E. C., Clement F., J. Am. Chem. Soc., 119, 5956-5957 (1997).

96) For example of anti elimination, see: Schwarz I., Braun M., Chem. Eur. J., 5, 2300-2305 (1999), and references cited.

97) For a related reaction, see: Catellani M., Chiusoli G. P., Castagnoli C., J. Organomet. Chem., 407, C30-C33 (1991).

98) For a related reaction, see: Burwood M., Davies B., Díaz I., Grigg R., Molina P., Sridharan V., Hughes M., Tetrahedron Lett., 36, 9053 9056 (1995).

99) For a related reaction, see: Campo M. A., Larock R. C., J. Am. Chem. Soc., 124, 14326-14327 (2002).

100) For a related stereomutation of the palladium(II) intermediate, see: Grigg R., Sridharan V., Stevenson P., Sukirthalingam S., Worakun T., Tetrahedron, 46, 4003-4018 (1990).

101) For a related stereomutation of the palladium(II) intermediate, see: McClure M. S., Glover B., McSorley E., Millar A., Osterhout M. H., Roschangar F., Org. Lett., 3, 1677-1680 (2001).

102) For a related isomerization of trans-organopalladium complex to cis isomer via the $\eta^{3}-\eta^{1}-\eta^{3}$ mechanism, see: Nishimura T., Ohe K., Uemura S., J. Am. Chem. Soc., 121, 2645-2646 (1999).

103) For a related reaction, see: Toyota M., Ilangovan A., Okamoto R., Masaki T., Arakawa M., Ihara M., Org. Lett., 4, 4293-4296 (2002).

104) For a related reaction, see: Glover B., Harvey K. A., Liu B., Sharp M. J., Tymoschenko M. F., Org. Lett., 5, 301-304 (2003).

105) For a related reaction, see: Sezen B., Sames D., J. Am. Chem. Soc., 125, 5274-5275 (2003).

106) For a related reaction, see: Ames D. E., Bull D., Tetrahedron, 38, 383-387 (1982).

107) For a related reaction, see: Pivsa-Art S., Satoh T., Kawamura Y., Miura M., Nomura M., Bull. Chem. Soc. Jpn., 71, 467-473 (1998).

108) For a related reaction, see: Park C.-H., Ryabova V., Seregin I. V., Sromek A. W., Gevorgyan V., Org. Lett., 6, 1159-1162 (2004).

109) Grigg R., Savic V., Tambyrajah V., Tetrahedron Lett., 41, 3003-3006 (2000).

110) Hughes C. C., Trauner D., Angew. Chem., Int. Ed., 41, 1569-1572 (2002).

111) Hennessy E. J., Buchwald S. L., J. Am. Chem. Soc., 125, 12084 12085 (2003).

112) Sezen B., Sames D., J. Am. Chem. Soc., 125, 10580-10585 (2003).

113) Ohno H., Takeoka Y., Miyamura K., Kadoh Y., Tanaka T., Org. Lett., 5, 4763-4766 (2003).

114) Boger D. L., Boyce C. W., Garbaccio R. M., Goldberg J. A., Chem. Rev., 97, 787-828 (1997).

115) Fowden L., Smith A., Phytochemistry, 8, 437-443 (1969).

116) Fujimoto Y., Irreverre F., Karle J. M., Karle I. L., Witkop B., J. Am. Chem. Soc., 93, 3471-3477 (1971).

117) Mamai A., Madalengoitia J. S., Org. Lett., 3, 561-564 (2001).

118) Schlag W.-R., Vilsmaier E., Maas G., Tetrahedron, 50, 3123-3138 (1994).

119) Shimamoto K., Ishida M., Shinozaki H., Ohfune Y., J. Org. Chem., 56, 4167-4176 (1991).

120) Morikawa T., Sasaki H., Hanai R., Shibuya A., Taguchi T., J. Org. Chem., 59, 97-103 (1994).

121) Galeazzi R., Mobbili G., Orena M., Tetrahedron: Asymmetry, 8, 133-137 (1997).

122) For chiral dirhodium(II)-catalyzed asymmetric synthesis, see: Doyle M. P., Austin R. E., Bailey A. S., Dwyer M. P., Dyatkin A. B., Kalinin 
A. V., Kwan M. M. Y., Liras S., Oalmann C. J., Pieters R. J., Protopopova M. N., Raab C. E., Roos G. H. P., Zhou Q.-L., Martin S. F., J. Am. Chem. Soc., 117, 5763-5775 (1995).

123) Grigg R., Rasul R., Redpath J., Wilson D., Tetrahedron Lett., 37 , 4609-4612 (1996).

124) Oppolzer W., Pimm A., Stammen B., Hume W. E., Helv. Chim. Acta, 80, 623-639 (1997).

125) Böhmer J., Grigg R., Marchbank J. D., Chem. Commun., 2002, 768 769 (2002).

126) For an excellent review on the cyclic carbopalladation, including related cyclopropanations, see: Negishi E., Copéret C., Ma S., Liou S.Y., Liu F., Chem. Rev., 96, 365-393 (1996).

127) For a review on the cyclopropanation of palladium carbenes, see: Reiser O., "Handbook of Organopalladium Chemistry for Organic Synthesis," Vol. 1, ed. by Negishi E., John Wiley \& Sons, New York, 2002, pp. $1561-1577$.

128) As shown in Chart 10, the cis cyclization to give 121 (Chart 14) would be the predominant process over the trans cyclization.

129) Ohno H., Hamaguchi H., Tanaka T., Org. Lett., 3, 2269-2271 (2001).

130) Ohno H., Ando K., Hamaguchi H., Takeoka Y., Tanaka T., J. Am. Chem. Soc., 124, 15255-15266 (2002).

131) Ma S., "Modern Allene Chemistry," Vol. 2, ed. by Krause N., Hashmi A. S. K., Wiley-VCH, Weinheim, 2004, pp. $614-619$.

132) For a pioneering work, see: Corey E. J., Boaz N. W., Tetrahedron Lett., 25, 3059-3062 (1984).

133) For a pioneering work, see: Caporusso A. M., Polizzi C., Lardicci L., Tetrahedron Lett., 28, 6073-6076 (1987)

134) For a pioneering work, see: Märkl G., Attenberger P., Kellner J., Tetrahedron Lett., 29, 3651-3654 (1988).

135) Marshall J. A., Adams N. D., J. Org. Chem., 62, 8976-8977 (1997).

136) D'Aniello F., Mann A., Taddei M., J. Org. Chem., 61, 4870-4871 (1996).

137) Montury M., Goré J., Synth. Commun., 10, 873-879 (1980).

138) Elsevier C. J., Meijer J., Tadema G., Stehouwer P. M., Bos H. J. T., Vermeer P., J. Org. Chem., 47, 2194-2196 (1982).

139) Elsevier C. J., Vermeer P., Gedanken A., Runge W., J. Org. Chem., 50, 364-367 (1985).

140) Mavrov M. V., Voskanyan E. S., Kucherov V. F., Tetrahedron, 25 , 3277-3285 (1969)

141) Caporusso A. M., Geri R., Polizzi C., Lardicci L., Tetrahedron Lett., 32, 7471-7472 (1991).

142) Joshi R. V., Zemlicka J., Tetrahedron, 49, 2353-2360 (1993).

143) Ohno H., Hamaguchi H., Tanaka T., Org. Lett., 2, 2161-2163 (2000)

144) Ohno H., Hamaguchi H., Tanaka T., J. Org. Chem., 66, 1867-1875 (2001)

145) Li A.-H., Zhou Y.-G., Dai L.-X., Hou X.-L., Xia L.-J., Lin L., Angew. Chem., Int. Ed. Engl., 36, 1317-1319 (1997).

146) Florio S., Troisi L., Capriati V., Suppa G., Eur. J. Org. Chem., 2002, 3793-3797 (2000)

147) Chemla F., Hebbe V., Normant J. F., Tetrahedron Lett., 40, 80938096 (1999).

148) Garner P., Park J. M., J. Org. Chem., 55, 3772-3787 (1990).

149) D’Aniello F., Schoenfelder A., Mann A., Taddei M., J. Org. Chem., 61, 9631-9636 (1996).

150) For a related work on catalytic enantioselective alkynylation of aldehydes, see: Frantz D. E., Fässler R., Carreira E. M., J. Am. Chem. Soc., 122, 1806-1807 (2000).

151) The starting amino alcohols $\mathbf{1 2 9}$ and $\mathbf{1 3 2}$ were readily prepared from natural amino acids through alkynylation of the corresponding aldehydes, see: ref. 20.

152) Ohno H., Hamaguchi H., Ohata M., Tanaka T., Angew. Chem., Int. Ed., 42, 1749-1753 (2003)

153) Ohno H., Hamaguchi H., Ohata M., Kosaka S., Tanaka T., Heterocycles, 61, 65-68 (2003).

154) Ohno H., Hamaguchi H., Ohata M., Kosaka S., Tanaka T., J. Am. Chem. Soc., 126, 8744-8754 (2004).

155) For a recent review, see: Evans P. A., Holmes A. B., Tetrahedron, 47 , 9131-9166 (1991).

156) For examples of seven-membered heterocycles, see: Duong T., Prager R. H., Tippett J. M., Ward A. D., Kerr D. I., Aus. J. Chem., 29,
2667-2682 (1976).

157) For examples for seven-membered heterocycles, see: Ishihara Y., Hirai K., Miyamoto M., Goto G., J. Med. Chem., 37, 2292-2299 (1994).

158) For examples for seven-membered heterocycles, see: Morís-Varas F., Qian X.-H., Wong C.-H., J. Am. Chem. Soc., 33, 7647-7652 (1996).

159) For examples of eight-membered heterocycles, see: Basil B., Coffee E. C. J., Gell D. L., Maxwell D. R., Sheffield D. J., Wooldridge K. R. H., J. Med. Chem., 13, 403-406 (1970).

160) For examples of eight-membered heterocycles, see: Vedejs E., Galante R. J., Goekjian P. G., J. Am. Chem. Soc., 120, 3613-3622 (1998).

161) For a recent review, see: Maier M. E., Angew. Chem., Int. Ed., 39, 2073-2077 (2000).

162) Tsuji J., Watanabe H., Minami I., Shimizu I., J. Am. Chem. Soc., 107, 2196-2198 (1985).

163) For a recent example, see: Yoshida M., Ihara M., Angew. Chem., Int. Ed., 40, 616-619(2001).

164) For a recent example, see: Labrosse J.-R., Lhoste P., Sinou D., J. Org. Chem., 66, 6634-6642 (2001).

165) For a recent example, see: Kozawa Y., Mori M., Tetrahedron Lett., 43, 1499-1502 (2002)

166) For an excellent review, see: Tsuji J., Mandai T., Angew. Chem., Int. Ed., 34, 2589-2612 (1995).

167) For a review, see: Kricka L. J., Ledwith A., Chem. Rev., 74, 101-123 (1974).

168) The trans-configuration of $\mathbf{1 6 9}$ was determined by NOE analysis as shown below.

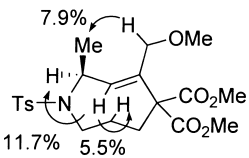

169) Ogoshi S., Tsutsumi K., Nishiguchi S., Kurosawa H., J. Organomet. Chem., 493, C19-C21 (1995).

170) Tsutsumi K., Ogoshi S., Nishiguchi S., Kurosawa H., J. Am. Chem. Soc., 120, 1938-1939 (1998)

171) In the reaction of propargylic carbonates, it is proposed that the first nucleophilic addition onto the $\eta^{3}$-propargylpalladium produces a metallacyclobutene, protonation of which generates the $\eta^{3}$-allylpalladium complex, see: Casey C. P., Nash J. R., Yi C. S., Selmeczy A. D., Chung S., Powell D. R., Hayashi R. K., J. Am. Chem. Soc., 120, $722-733(1988)$

172) Tsutsumi K., Kawase T., Kakiuchi K., Ogoshi S., Okada Y., Kurosawa H., Bull. Chem. Soc. Jpn., 72, 2687-2692 (1999).

173) Baize M. W., Blosser P. W., Plantevin V., Schimpff D. G., Gallucci J. C., Wojcicki A., Organometallics, 15, 164-173 (1996).

174) Tanaka T., Wakayama R., Maeda S., Mikamiyama H., Maezaki N., Ohno H., Chem. Commun., 2000, 1287-1288 (2000).

175) Ohno H., Maeda S., Okumura M., Wakayama R., Tanaka T., Chem. Commun., 2002, 316-317 (2002).

176) Ohno H., Wakayama R., Maeda S., Iwasaki H., Okumura M., Iwata C., Mikamiyama H., Tanaka T., J. Org. Chem., 68, 5909-5919 (2003).

177) Ohno H., Okumura M., Maeda S., Iwasaki H., Wakayama R., Tanaka T., J. Org. Chem., 68, 7722-7732 (2003).

178) Ohno H., Iwasaki H., Eguchi T., Tanaka T., Chem. Commun., 2004, 2228-2229 (2004).

179) Ohno H., Mimura N., Otaka A., Tamamura H., Fujii N., Ibuka T., Shimizu I., Satake A., Yamamoto Y., Tetrahedron, 53, 12933-12946 (1997).

180) Ohno H., Ishii K., Honda A., Tamamura H., Fujii N., Takemoto Y., Ibuka T., J. Chem. Soc., Perkin Trans. 1, 1998, 3703-3716 (1998).

181) For authors' recent contribution on the allene chemistry, see: Hamaguchi H., Kosaka S., Ohno H., Tanaka T., Angew. Chem., Int. Ed., 44, 1513-1517 (2005).

182) For authors' recent contribution on the allene chemistry, see: Ohno H., Mizutani T., Kadoh Y., Miyamura K., Tanaka T., Angew. Chem., Int. Ed., 44, 5113-5115 (2005).

183) For authors' recent contribution on the related enyne chemistry, see: Ohno H., Yamamoto M., Iuchi M., Tanaka T., Angew. Chem., Int. Ed., 44, 5103-5106 (2005). 